IZA DP No. 5598

Risk, Institutions and Growth:

Why England and Not China?

Avner Greif

Murat lyigun

Diego Sasson

March 2011 


\title{
Risk, Institutions and Growth: Why England and Not China?
}

\author{
Avner Greif \\ Stanford University \\ Murat lyigun \\ University of Colorado \\ and IZA \\ Diego Sasson
Goldman Sachs
}

\author{
Discussion Paper No. 5598 \\ March 2011
}

\author{
IZA \\ P.O. Box 7240 \\ 53072 Bonn \\ Germany \\ Phone: +49-228-3894-0 \\ Fax: +49-228-3894-180 \\ E-mail: iza@iza.org
}

\begin{abstract}
Any opinions expressed here are those of the author(s) and not those of IZA. Research published in this series may include views on policy, but the institute itself takes no institutional policy positions.

The Institute for the Study of Labor (IZA) in Bonn is a local and virtual international research center and a place of communication between science, politics and business. IZA is an independent nonprofit organization supported by Deutsche Post Foundation. The center is associated with the University of Bonn and offers a stimulating research environment through its international network, workshops and conferences, data service, project support, research visits and doctoral program. IZA engages in (i) original and internationally competitive research in all fields of labor economics, (ii) development of policy concepts, and (iii) dissemination of research results and concepts to the interested public.
\end{abstract}

IZA Discussion Papers often represent preliminary work and are circulated to encourage discussion. Citation of such a paper should account for its provisional character. A revised version may be available directly from the author. 


\begin{abstract}

\section{Risk, Institutions and Growth: Why England and Not China?}

We analyze the role of risk-sharing institutions in transitions to modern economies. Transitions requires individual-level risk-taking in pursuing productivity-enhancing activities including using and developing new knowledge. Individual-level, idiosyncratic risk implies that distinct risk-sharing institutions - even those providing the same level of insurance - can lead to different growth trajectories if they differently motivate risk-taking. Historically, risk sharing institutions were selected based on their cultural and institutional compatibility and not their unforeseen growth implications. We simulate our growth model incorporating England's and China's distinct pre-modern risk-sharing institutions. The model predicts a transition in England and not China even with equal levels of risk sharing. Under the clan-based Chinese institution, the relatively risk-averse elders had more control over technological choices implying lower risk-taking. Focusing on non-market institutions expands on previous growththeoretic models to highlight that transitions can transpire even in the absence of exogenous productivity shocks or time-dependent state variables. Recognizing the role of non-market institutions in the growth process bridges the view that transitions are due to luck and the view that transitions are inevitable. Transitions transpire when 'luck' creates the conditions under which economic agents find it beneficial to make the choices leading to positive rates of technological change. Luck came in the form of historical processes leading to risk-sharing institutions whose unintended consequences encouraged productivity-enhancing risk-taking.
\end{abstract}

JEL Classification: $\quad$ O10, O31, O43, N10

Keywords: institutions, risk, growth, development

Corresponding author:

Avner Greif

Department of Economics

Stanford University

Stanford, CA 94305

USA

E-mail: avner@stanford.edu 
"Theories of economic growth have failed. These theories are built around a positive rate of technological change, either simply assumed or generated ... by ... assumption."

Robert E. Lucas Jr., 2002, p.110.

"Variations in the economic performance across countries (e.g, earlier industrialization in England than in China) reflect initial differences in geographical factors and historical accidents and their manifestations in variations in institutional, demographic and cultural factors..."

Oded Galor, 2005, Ch. 4.

\section{Introduction}

What has led to transitions from pre-modern economies to modern economies? Growththeoretic models identify two important causes of transition from pre-modern economies to modern ones. In multiple-equilibria growth models, a low-growth economy is a stable equilibrium because decreasing relative risk aversion implies that agents are too risk-averse to choose the modern, high-risk, high-return technology. A transition to a high-growth economy requires exogenous "accidents and good fortune" that disables the low-growth equilibrium (Becker et al., 1990, p. 14) . In 'endogenous transition' models, by contrast, low-growth equilibria are unstable and a "transition from stagnation to growth is largely an inevitable outcome of the process of development" (Galor, 2007, p. 472). In particular, time-dependent changes in relative prices, technology, or wealth trigger a transition. ${ }^{1}$

Both the multiple equilibria and the endogenous transition models have been criticized for failing to explain transitions. Multiple-equilibria models invoke accidents (Galor 2005, pp. 176-7) while endogenous transition models "are built around a positive rate of technological change, either simply assumed or generated as an equilibrium outcome by the assumption of [for example] constant or increasing returns to the accumulation of knowledge" (Lucas, 2002, p. 110).

This paper theoretically analyzes and historically evaluates endogenous transitions in the absence of accidental changes in wealth or productivity, time-dependent variables, efficient markets, or knowledge of modern technologies. It focuses on how risk-sharing

${ }^{1}$ See the review in Galor (2005). For some important contributions to both lines of research, see Kremer (1993), Jones (2001), Galor and Weil (2000), Hansen and Prescott (2002), Gollin, Parente and Rogerson (2002) and Galor (2005). 
institutions as well as their forms and functions influence individual-level incentives to engage in risky, productivity-enhancing activities. Productivity enhancements require cultivators, producers, and traders to conduct risky experiments. ${ }^{2}$ Yet, low levels of wealth and decreasing relative risk aversion imply that individual-level risk taking, while socially beneficial, is not likely to be individually rational prior to a transition. Risksharing institutions that make risk-taking individually rational can increase productivity and lead to a transition. ${ }^{3}$ Whether a transition transpires directly depends only on the choice of institutions at the social level and choices about risk-taking at the individual level.

We model this argument using an OLG 'technology transition' model in which economic agents choose how to employ their capital. ${ }^{4}$ An agent's choice determines the probability of higher future capital productivity. This higher productivity is due to a complex process of the creation of new productivity-enhancing knowledge from which we abstract away. Choosing the 'traditional' technology is less likely to generate new knowledge but is also less risky. Experimenting is more risky but is more likely to generate new knowledge. This knowledge increases the capital productivity of the agent who discovers it and, once this knowledge spreads, it increases capital productivity more generally. A pre-modern economy is one in which most agents choose the 'traditional' technology and the rate of productivity growth is correspondingly low. A modern economy is one where all agents experiment and choose the 'risky' technology leading to a high rate of productivity growth. In a transition, the number of agents choosing the risky technology increases over time causing an increase in the rate of productivity growth.

Positive externalities imply that agents will employ less capital than socially optimal in the risky technology. Decreasing relative risk aversion implies that poor agents select the traditional technology. If sufficiently many agents are poor, a transition will therefore not transpire and the economy stagnates. A risk-sharing institution can mitigate the impact of low wealth and risk aversion on some agent's technological choices and initiate an endogenous transition. More specifically, a risk-sharing institution that sufficiently increases risk-taking causes a transition. For reasons discussed below, two institutions that provide the same risk-sharing, can nevertheless have different risk-taking implications.

\footnotetext{
${ }^{2}$ Such risky experimentation was particularly important in the past because the epistemological basis of technology was narrow (Mokyr, 2002). The ability to predict was lower because causal relations were not well understood. Along these lines, Acemoglu and Zilibotti (1997) examine the relations between the indivisibility of risky projects, diversification, and growth.

${ }^{3}$ There was, of course, some risk-taking in all pre-modern economies. Some risky activities such as warfare and exploration were taken by those who could pay others to bear the personal cost of failure. Necessity and various means to mitigate risk (particularly in commerce) motivated others to pursue risky ventures. Our model allows - and simulations reveal - some risk taking prior to the transition.

${ }^{4}$ Analytically, we focus, without loss of generality, on capital productivity rather than human capital to capture choices with positive externalities (e.g., cultivation techniques).
} 
Risk-sharing institutions - in particular, their effectiveness and forms - can determine if and when a transition to a modern economy transpires.

This causal relation between risk, non-market institutions, and transitions is intuitively appealing. It captures the limited growth potential of relying on 'traditional' ways of pursuing economic activities. Following the beaten path is safe, but unlikely to lead to new destinations. Risking to travel off the beaten path is more likely to lead to new productivity-enhancing insights or innovations. To keep our model parsimonious, however, we don't attempt to formally capture this complex process. Instead, agents choose between technologies with different productivity shocks. Yet, a reasonable interpretation of this formulation is that choosing a high-risk technology amounts to generating new technological and organizational knowledge. ${ }^{5}$

We evaluate the historical relevance of transitions' institutional conditionality by modeling China's and England's pre-modern institutions, simulate their implications and qualitatively evaluate their time-series and cross-section implications.

In both economies, concern with the social order and compassion led to effective, yet distinct, risk-sharing institutions. In China, poor relief was predominantly provided by lineages (clans) headed by their elders. In England, beginning in the 16th century, the state gradually displaced the Church and voluntary associations as the main provider of poor relief. The Old Poor Law of 1601 formalized this system which, with some modifications, prevailed until 1834. ${ }^{6}$ Similar transitions transpired elsewhere in Europe but England's system was particularly effective (Solar, 1995).

In China and England, the forms that these institutions took were not selected by their (unforeseen) growth implications. Their institutional forms were selected by the state based on their compatibility with the prevailing culture and institutions. ${ }^{7}$ A clan-based risk-sharing institution indeed evolved in the collectivist, lineage-based Chinese society while a state-based risk-sharing institution evolved in the individualistic, nuclear-family based English society. It is therefore appropriate to consider these risk-sharing institutions as exogenous in examining their growth implications. ${ }^{8}$

The evolution of different risk-sharing institutions highlights an interpretation of our analysis as bridging the view that transitions are due to luck and the view that transitions are inevitable. Transitions transpire when 'luck' creates the conditions under which eco-

\footnotetext{
${ }^{5}$ Similarly gratifying is the observation that transition does not depend on incentives provided by efficient markets. An integral part of a transition is the development of the knowledge required for improving markets.

${ }^{6}$ Voigtländer and Voth (2006) found that the Old Poor Law did not influence England's industrialization by increasing wages.

${ }^{7}$ For one perspective on why institutional dynamics are a historical process in which past cultural and institutional elements influence subsequent institutions, see Greif (1994, 2006, chapter 7).

${ }^{8}$ Institutions governing one transaction (i.e., poor relief and social order) tend to have unintended consequences on behavior in other transactions, i.e., risk-taking (Greif, 2006).
} 
nomic agents find it beneficial to make the choices leading to a positive rate of technological change. ${ }^{9}$ Luck did not come in the form of a random draw of knowledge or wealth but in the form of historical processes leading to risk-sharing institutions whose unintended consequences encouraged productivity-enhancing risk-taking. Transitions were conditional on having risk-sharing institutions that increased the rate of productivity growth. ${ }^{10}$

Our simulations and historical analyses confirm the importance of risk-sharing institutions in transitions to a modern economy. China's lineage-based institution implied more risk-sharing prior to the introduction of the Old Poor Law. Yet, it was relatively ineffective in promoting risk-taking because lineages' elders had, by law and custom, strong influence on technological choices made by their lineages' young members. Because older people tend to be more risk averse than younger ones, the lineage-based institution led to less risk taking than if the young were in charge. ${ }^{11}$ Our simulations reveal that if the Chinese and the English institutions supplied the same level of risk-sharing, an eleven percent initial difference between the risk aversion of the young and the old was sufficient to prevent China from embarking on a transition to a modern economy. To initiate a transition, the Chinese institutions would have had to provide, roughly speaking, about twice the risk sharing of the English ones. ${ }^{12}$ This finding highlights the impact of culture on institutional forms (e.g. how risk-sharing is provided) and that institutional forms influence outcomes (e.g., risk-taking) beyond their impact of institutional functions (e.g., level of risk-sharing). ${ }^{13}$

This analysis demonstrates the historical relevance of the causal relations between risksharing institutions, knowledge, and transitions. It is also reassuring to note the empirical confirmation of the model's qualitative time-series and cross-section predictions. Our

${ }_{9}^{9}$ Previous works in economic history have focused on an endowment windfall due to discoveries (e.g., Pomeranz 2000), better informal contract enforcement institutions and the enlightenment (Mokyr 2005, 2006), and higher mortality rates which increases per-capita incomes (Voigtländer and Voth 2006).

${ }^{10}$ On the role of risk taking in economic growth, see, for example Hausmann and Rodrik 2003; Iyigun and Rodrik 2005.

${ }^{11}$ Contemporary empirical analyses found that the elders are more risk averse. Einav and Cohen (2007) found that risk aversion declines after the age of 18 and increases after the age of 48. See also Graham, Harvey, and Puri (2008); Halek and Eisenhauer (2001); Riley and Chow (1992). Early twentieth-century decisions by Chinese peasants regarding crops and labor were influenced by risk aversion (Wiens, 1976), while in the modern economy, low risk-aversion fosters entrepreneurship (van Praag and Cramer, 2001).

That noted, it is possible that the link between age and risk aversion is spurious, and more of a manifestation of changes in risk aversion driven by differences in the consumption patterns and habits of the old versus the young. We are agnostic on this point, because our model does not ride on the assumption that older people are simply more risk averse. As we shall elaborate further below, we can accomodate preferences such that individuals become more risk averse in old age not because they are old but, for instance, due to their higher consumption habits.

${ }^{12}$ Risk sharing is here measured as the reduction - compared to the individualistic economy - in the standard deviation of innovations to the process of productivity. Consult the model section for details.

${ }^{13}$ On the relations between culture and institutions, see, for example, Greif (1994, 2006); Lal (1998); Zak and Knack (2001); Acemoglu et. al. (2001); Rodrik, et. al. (2004); Helpman (2004); North (2005); Tabellini (2005); Guiso, Sapienza and Zingales (2006). 
analysis accounts for observations that are difficult to reconcile when viewing transitions as either accidental or inevitable. Among these are the surge in China's contributions to new knowledge under the Song Dynasty (960-1279 CE), their subsequent decline, England's leadership in innovations rather than inventions during the Industrial Revolution, and the capacity of European states to rapidly imitate England. Our analysis reveals that risksharing institutions may have been important in rendering England, rather than China, the first modern economy.

Our theoretical analysis assumes that China and England differed only by their risksharing institutions. Historically, however, these two societies differed in many ways. Some of these distinctions, such as differences in cultural attitudes toward risks and inventions (e.g., Mokyr, 2002, 2006) and the institutional foundations of the market (Greif, 2005) might be endogenous to the institutional distinctions we focus on. Other distinctions such as political institutions or access to natural resources (Pomeranz 2000) were not. The possible importance of such distinctions notwithstanding, it is important to note that China was economically ahead, or not far behind, England prior to the 16th or 17th century. Urbanization rates suggest that around $1000 \mathrm{CE}$, China was more economically developed than Europe. Grain-equivalent wages in China, for example, were $87 \%$ of the English in 1550-1649 (Broadberry and Gupta, 2006) and only during the 19th century were European markets better integrated than those in China (Shiue and Keller, 2007).

The rest of the paper is as follows. Section 2 provides a historical background on risk-sharing institutions and elders' authority in England and China. Section 3 describes the model. Section 4 provides the numerical results of our model. Section 5 lays out supporting historical observations, and section 6 concludes.

\section{Social Structures, Risk-Sharing Institutions and Knowl- edge}

Over the last millennium, institutions insuring against idiosyncratic individual-level risks evolved differently in China and England. Three observations about these non-market institutions are presented in this section. First, lineages, dominated by their elders, prevailed in pre-modern China, but not England. More economic choices involving risk-taking were made by elders. Second, after $1601 \mathrm{CE}$, the main risk-sharing institutions in these countries were state-based in England and lineage-based in China. Third, risk-sharing institutions influenced risk-taking and hence the creation of new productivity-enhancing knowledge. These observations underpin the assumptions we later make in modeling these risk-sharing institutions. 


\subsection{Social Structures}

By 1000 CE, social structures in England and China had already differed. In England, generally speaking, there were no large, kin-based social structures such as lineages and tribes. The nuclear family structure predominated. In China, however, lineages (clans) have been important economic, social and cultural units up to the modern period.

The elimination of large, kin-based social structures in Europe was due to the dogma adopted by the Church regarding marriage, although even the secular law reflected features that presumably limited optimal family size (Goody 1983; Ekelund et al., 1996; Greif 2006). The Roman Catholic Church dogma discouraged practices that enlarged the family, such as adoption, polygamy, concubinage, divorce, and remarriage. The Church also restricted marriages among the kin (consanguineous marriages), often up to the seventh degree, and prohibited unions without the bride's explicit consent. ${ }^{14}$ Kin marriages and parents' ability to retain kinship ties through arranged marriages were historically important means of maintaining kinship groups. But, as Goody (1983) first observed and Ekelund et al. (1996, p. 93, 94) later stated, "land acquisition and estate building through consanguineous marriages became increasingly common in the Middle Ages... [t] he Church hoped that by further restricting marital options, the incidence of heirs would decrease, thereby increasing the likelihood of inheritance for itself." Moreover, even European secular laws worked to limit family size: "While secular law did not prohibit endogamy, it did regulate the ability of children from such marriages to inherit an estate."

The European family structures did not evolve monotonically toward the nuclear family, nor was their evolution geographically and socially uniform. Yet, by the late medieval period, the nuclear family became the norm in Western Europe (e.g., Mitterauer et. al., 1982; Goody, 1983; Ekelund et. al., 1996; Herlihy, 1985; Greif, 2006, chapter 8). The (Germanic) Salic law of the sixth century denied legal rights to anyone not affiliated with a large kinship group. By the eighth century, the term 'family' among the Germanic tribes denoted one's immediate family. Tribes and lineages, by and large, were no longer institutionally relevant (Guichard and Cuvillier, 1996). By the 10th century, the English King issued a law mandating every male to join a group that would guarantee his appearance in court, suggesting that kinship groups could no longer be held accountable as was the case when the Salic law was specified.

Quantitative evidence from later centuries also reveals a decline of large kinship groups. English court rolls from the thirteenth century reflect that cousins were not more likely than non-kin to be in each other's presence (Razi, 1993). The English poll-tax records

\footnotetext{
${ }^{14}$ In the late Roman period, the law prohibited marriage among relatives to the 3rd degree, implying that first cousins could marry. The Roman law also required consent to these marriages. Herlihy (1985), pp. $7-8$.
} 
of 1377 indicate that there were approximately 2.3 individuals over the age of thirteen per-household (Schofield, 2003, p. 83). The mean household size in five English parishes in the 16th century ranged from 4.05 to 6.05 and that of 100 parishes from the 16 th to the 19 th century was 4.79 . Only about 10 percent of the households had a resident kin (Laslett, 1969, pp. 204, 207, 218). ${ }^{15}$ Large kinship groups remained important only among nobility and on the fringes of Europe (e.g., Scotland).

The nuclear family was also a basic unit of social organization in pre-modern China. But larger, kin-based social structures were common and remained culturally, socially, politically and economically prominent well into the modern period. ${ }^{16}$ Indeed, the ideology and practice of patrilineal descent, filial pity, and ancestor worship was the hallmark of Chinese society and culture (e.g., Freedman, 1958). Furthermore, social and economic relations were commonly kinship-based and lineages provided members with local public goods such as protection and education (e.g., Hamilton, 1990). The state, whose magistrates were positioned at the county level and above, used kin-based organizations for tax collection and considered male descendants of a household a jointly liable tax unit.

The structure of Chinese kin-based social structures evolved over time and was not uniform across different regions. In particular, there was a gradual shift from communal families to lineage organizations. The communal family are the kinship group referred to the most during the Tang (618-690 CE, 705-907 CE) and the Song (960-1279 CE) dynasties. These were domestic units that had not divided - in terms of property or membership - for five, six, or even ten generations. Some communal families included hundreds and even thousands of members. The state praised communal families as an ideal form of organization and supported exceptional ones through tax exemptions. Communal families are still often reflected in the historical records of later dynasties but we have no quantitative measure of how many communal families existed at any point in time. Given the complexity of supporting, organizing and maintaining the coherence of such large groups, really large communal families must have been relatively rare and it seems that they gradually vanished. ${ }^{17}$

After the Song dynasty (960-1279 CE), lineage organizations became common. These looser associations of relatively large numbers of kin "were the predominant form of kinship organizations in late imperial China" (Ebrey and Watson, 1986, pp. 1, 6; Watson 1982). Detailed information on the share of the population with lineage affiliation is not available

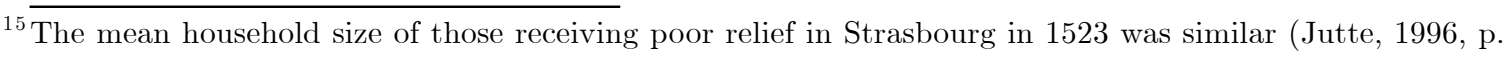
$382)$.

${ }^{16}$ This discussion particularly draws on Smith (1987); Ebrey and Watson (1986); Szonyi (2002); Freedman (1958); Watson (1982); Liu (1959).

${ }^{17}$ By tracing clans' life-cycle, Fei and Liu (1982, p. 399) concluded that the critical maximum size (CMV) of a lineage is about 1,400 males and females which is about 300 families. Abramitzky (2008) presents an empirical analysis of contractual problems in large, risk-sharing organizations. 
but lineages were common in southern China, less common at the center and least common in northern China.

In addition, those with sufficient means often maintained large households, either in the form of a 'stem' or an extended family. A stem family included parents and at least one married son and his family and averaged ten people (Fei and Liu 1982). The extended family encompassed members of several families related through the male line. Members often lived in a family compound, had common property and an internal dispute-resolution mechanism. Such larger households were culturally esteemed and economically beneficial to their members, practically because they consolidated assets and local political power under family control.

In all these social structures, fathers, and elders more generally, exerted various degrees of authority even over their adult children and control over family assets. In Imperial China, "the father had paternal authority over his children, while the children had the duty to practice filial behavior and to support their parents in old age. The family head had absolute authority and discretion. This kind of power was not only confirmed by the rule of propriety $(l i)$... but was also protected by state and customary law. These rules provided him with arbitrary power over family property ... [and] in making decisions concerning all aspects of family matters... all earning of family members had to be handed to him.... Even members who settled somewhere else or were temporarily absent, sent their surplus earnings to him" (Chen 1999, pp. 250-1).

In China, the preferences of the elders had a large and institutionalized influence on the economic actions by young adults. In sharp contrast, adult sons were not under their fathers' authority under English law and customs, long before the 17th century.

\subsection{Risk-sharing Institutions}

Throughout history, risk-sharing non-market institutions have been created to maintain social order and help those in need. ${ }^{18}$ These details - institutional forms - were endogenous to these societies' pre-existing cultural and institutional elements. In particular, the absence and presence of large kinship groups determined the cost to the rulers of establishing different risk-sharing institutions. In England, risk-sharing institutions based on large kin groups were a costly proposition given the absence of such groups. This was not the case in China. Indeed, the English (and more broadly, the European) institutions were not kin-based while in China they were.

Specifically, in Europe prior to the 16th century, secular and religious organizations - monasteries, fraternities, mutual-insurance guilds, and communes - assisted the poor or their members in times of need. They provided individuals with such services as poor

\footnotetext{
${ }^{18}$ We shall elaborate more on this point in subsection 3.2.4 below.
} 
relief and unemployment and disability assistance. In the late medieval period, the total capacity of England's monasteries for grain storage was more than what was required to sustain the Kingdom's population for a year (Fenoaltea, 1976). In the early 16th century, the majority of the commoners in England belonged to fraternities and guilds that provided social safety nets (Richardson, 2005). The same pattern seems to have prevailed elsewhere in Europe (Reynolds, 1984; Brenner, 1987). Getting relief from these risk-sharing institutions was, however, uncertain as they were either voluntarily provided by charity organizations (e.g., by the Church) or cooperatively financed by working people without much wealth.

This system of poor relief came under pressure due to increasing population and urbanization during the 16th century and alternatives were sought through legislation and other public initiatives. The Wars of Religion contributed to its decline as many of the corporations through which insurance was provided were associated with the Catholic Church and Protestant rulers dismantled them. During the Counter-Reformation, Catholic rulers also confiscated the properties of these corporations to finance their wars against the Protestants. Europe lost its system of poor relief. In England, Henry VIII established the Anglican Church, dissolved the monasteries in 1536-40, and shut down all religious guilds, fraternities, almshouses, and hospitals in 1545-49. These actions "destroyed much of the institutional fabric which had provided charity for the poor in the past" (Slack, 1990, p. 8).

Social order was undermined by the lack of an effective poor relief system and population growth pressured wages and increased poverty. States responded by creating alternative, state-based systems during the 16th century. Local administrative bodies within the European states, such as parishes and cities, were required by law to care for their poor. In England, the Poor Law Act of 1601 (the Old Poor Law) formalized the emerging alternative system which lasted, with some modifications, until 1834. Each parish was authorized and obliged to levy a property tax to care for the poor (Boyer, 1990).

Shifting the responsibility for poor relief to the state (via local administrators) was a European phenomenon and poor relief systems similar to England's were established elsewhere (Geremek, 1997; Jutte, 1996; de Vries and de Woude, 1997, pp. 654-664). Yet, the English Poor Law system was more reliable and generous than the continental ones. In England, expenses were financed through a variable poor rate on the assessed rental value of local real estate property and most aid was given without forcing the recipient to move to the poor house. ${ }^{19}$ Continental poor relief, by contrast, was financed from a variety of sources: voluntary donations, capital income, subsidies from local and national

\footnotetext{
${ }^{19}$ Those who financed the Poor Law had no legal rights to influence risk taking. Moreover, farmers who took risk (by specializing in grains) had the political power to transfer the cost of insurance on to others (Boyer, 1986).
} 
governments, and general tax revenues. Funding was, therefore, less reliable. Furthermore, the legal right to relief was well defined in England while rights were vaguely defined, less credibly assured, and generally at the discretion of local authorities on the continent.

Annual spending on poor relief in England was about 1 percent of national income in the 17 th century and about 2.5 percent at its peak during the 19 th. At that time, it supported about 11 percent of the population and may have boosted average income of the bottom 40 percent by 14 to 25 percent. Expenditure per capita was 7.5 times higher than in France in the 1780s, 2.5 times higher than in the Netherlands in the 1820s, and 5 times higher than in Belgium in the 1820s. (Boyer, 1990; Mokyr, 2002). ${ }^{20}$ England's exceptionalism reflects distinct needs in the late 16th century when these systems were created. While peasantry and other 'customary' labor relations that insured the poor still dominated in other European states, the transition to wage laborer had already begun in England. ${ }^{21}$

Indeed, the evidence reveals that the poor were better secured after the implementation of the Poor Law in the 1620s. The elasticity of mortality with respect to real wages was negative and statistically significant from 1540 to 1640 but it was basically zero from 1640 to $1740 .^{22}$ The break-point in the trend occurred in 1625 and was due to better poor relief, and not higher real wages, reduced variance of grain output, increased urbanization, or changing climate (Kelly and Ógrada 2008). The death rate actually declined in England during the first half of the eighteenth century (Razzell 1994), while in China it was stable (Lee and Feng 1999). The relative importance of better nutrition and change in mortality during this period is still debated, but the evidence indicates that nutrition "should be regarded as one in a battery of factors, often interacting, which played a key rule in Britain's mortality transition" (Harris, 2004, p. 380). ${ }^{23}$

Imperial China also experienced great diversity and changes in its poor relief institutions. ${ }^{24}$ The state sporadically financed general or medical aid to the old, poor, sick, and disabled. Buddhist monasteries and temples provided medical service, fed the hungry and sheltered the aged and decrepit. Their support, however, was uncertain as they fed any poor including 'undeserving' ones. Benevolent societies were established after 1580, par-

${ }^{20}$ An extensive network of private charity suggests the limits of public relief but it contributed to social order despite the economic transition.

${ }^{21}$ On these and other aspects of the system see, for example, Boyer (1986); Slack (1990); Solar (1995). Patriquin (2006) compares the English case with that of Scotland and Ireland.

${ }^{22}$ Nicolini (2007); information from Parish's registers is available from 1540. See Landers (1987) about London.

${ }^{23}$ The role of better nutrition in this decline has been particularly emphasized by McKeown and his co-author and surveyed in Harris (2004). Smith (2008) emphasized the positive role of the Poor Law in reducing risk of labor migration.

${ }^{24}$ This discussion particularly draws on Smith (1987); Ebrey and Watson (1986); Szonyi (2002); Freedman (1958). We are not familiar with any quantitative analysis of these kinship organizations' relative importance. 
ticularly by members of the mercantile elite and the gentry. Yet, their forms and functions were often rigid and did not adjust to various needs.

In China, the major source of aid to the poor, the sick, and the aged were kinship groups. The role of communal and extended families in providing insurance is transparent from their internal organization. In such families, all property was held in common and the "underlying principle was distribution of income to all members equally according to need, just as though they were members of a small family" (Ebrey and Watson, 1986, p. 33). The young provided labor while the elders controlled all assets and had the legal and customary rights to make communal decisions.

In many respects, the lineages were the functional successors of communal families. They similarly exerted considerable legal and customary control over their members, provided them with public goods such as education, held common property, and acted as social and political units. In pre-modern China, a lineage "performs many functions related to education, ceremony, social security, and maintenance of law and order. Whereas now most of these functions are performed by the government, the clan was a primary social group (or organization) through which these functions were carried out before the art of government was perfected" (Fei and Liu, 1982, p. 375).

After the eleventh century, lineages were the most common and reliable source of poor relief. The first lineage charitable estate was established by Fan Chung-yen (989-1052 CE). Such estates were considered by the state and their members as the lineage's property. Yet, they were not commonly owned corporations but were controlled and managed by the elders of the lineage's prominent families. Income was used to finance lineage rituals and provide members with education, income, and support for weddings, burials and illness. Members in poverty received additional benefits such as free lodging. The state motivated lineages to care for its poor by considering it legally responsible for crimes committed by its members.

\subsection{Risk Taking and Knowledge}

Risk-sharing institutions might theoretically foster risk taking, knowledge, and productivity. Indeed, increases in useful, productivity-enhancing knowledge characterized the productivity growth leading to the modern economy (Mokyr, 1990, 2002). The puttingout system, turnpike trusts, drainage projects, the factory system, the steam engine, the New Husbandry, and the joint stock companies directly increased production and/or productivity. Behind these changes was new knowledge of, or the correct belief in, their benefits. Gaining this new, productivity-increasing knowledge, however, is risky. It is risky for an individual to invest in discovering new productivity-enhancing (technological, organizational, or commercial) knowledge. Implementing existing knowledge often implies 
risk as well (e.g., long-distance trade). Yet, a familiar risk is subjectively less intimidating than an unfamiliar one.

We often consider the patent system as the main means to induce risky investment in discovering new useful knowledge. Yet, patent systems were rare and ineffective in pre-modern economies. Even in England, an acceleration in patenting began only by 1757 (Sullivan, 1989) while the transition to modern growth began in the seventeenth century (Clark, 2005). By and large, the new knowledge that increased productivity in pre-modern economies reflected the input of many individuals who took personal risks in 'deviating' from the conventional ways of 'doing things' and discovered productivityenhancing knowledge. Pursuit of risky innovations and inventions contributed to the knowledge base that others acquired through observation, imitation, and education.

The high personal risk associated with developing new knowledge during the English transition is suggested by the evidence on inheritances. The inheritances left by English entrepreneurs (from 1700 to 1850) are "consistent with the intuitively appealing hypothesis that entrepreneurs in the modern sector suffered a higher failure rate, but when they struck it big, they did so on a larger scale" (Mokyr, 2006, p. 31). The risk was sufficiently high that even wealthy individuals sometime lost all their property and ended relying on poor relief. One wealthy individual who took risks and paid dearly was "William Radcliffe, a Derbyshire 'improver of cotton machinery,' who bought Samuel Oldknow's mill after the latter's bankruptcy, and apparently died poor after a roller-coaster career; another was Samuel Hall, a cotton-spinner and engineer who died in 'very reduced circumstances.' The cotton merchant Thomas Walker had to live his final years from a bequest. Perhaps the most spectacular example of a failed entrepreneur was the highly eccentric Archibald Cochrane, earl of Dundonald, who spent his family's fortune on his ill-fated chemical business. More than anything, however, Cochrane was unlucky. Somewhat comparable was the case of Henry Fourdrinier, a well to-do London stationer who gambled on the main innovation in paper-making of his age, spent $£ 60,000$ on the business and failed in 1810. Both Cochrane and Fourdrinier are thus examples of a significant negative private return on entrepreneurship" (Mokyr, 2006, pp. 24-5, Mokyr, 2010).

Given the personal risk of pursuing new, productivity-enhancing activities, it is reasonable that risk-sharing institutions mattered. Risk-sharing institutions can encourage risk-taking by individuals without the wealth required for self-insurance. Indeed, the number of individuals of modest means that took the risk of creating new knowledge during one of the most important part of the transition, the Industrial Revolution, was far from negligible. There were 333 'great inventors' who were active after 1790 and were born prior to 1845 in Britain and the USA (that also had a Poor Law system). ${ }^{25}$ Some 38

\footnotetext{
${ }^{25} \mathrm{~A}$ 'great inventor' is an individual who was included in biographical dictionaries because of his or her
} 
percent of these great inventors were of modest means. ${ }^{26}$ More generally, the poor, as the largest group in England, made economic decisions involving risk that, taken as a whole, mattered. Economic agents who were not wealthy had to decide, for example, whether to work in seasonal occupations, whether to adopt new agricultural methods, to transition to wage labor or to specialize.

Finally, as our model shall illustrate below, risk-sharing institutions increase the expected return to the wealthy from investing in the creation of new knowledge and taking out productivity enhancing activities by reducing the likelihood of violent responses from those economically disadvantaged by the process of change. The cost to the wealthy of risk-taking activities leading to new technological, organizational and commercial methods decline when those with meager means are protected from the implied economic change. Indeed, despite the major transformation that England experienced during its transition, it was surprisingly peaceful. ${ }^{27}$ A Poor Law that supported between 5 to 15 percent of the population at any time (Solar, 1995, p. 8) probably contributed a great deal to a relatively peaceful economic transition. "While there was some resistance to enclosure, the English were, by continental or Irish standards, quite easily separated from the land in the seventeenth and eighteenth centuries" (Solar, 1995, p. 9). Similarly, there was relatively little popular resistance to other major transformations such as the decline in the putting-out system, the introduction of hourly wage or the New Husbandry. England was remarkably peaceful during a transition that destroyed numerous traditional occupations and shifted risk toward the poor by increasing wage labor and eliminating many of their small landholdings and communal rights.

Between $210 \mathrm{BCE}$ and $1900 \mathrm{CE}$, there were as many as 225,887 recorded armed rebellions in China (Deng 2000, p. 7) and famines led to food riots (Li 1982, Wong 1982). A 17th century Chinese scholar and administrator explains: "The reason that peace does not prevail among the people is because of differences in wealth. The poor are often not capable of supporting themselves, and yet the rich are continually fearful of others' demands upon them, and tend to be tightfisted. It is this which gives rise to the mentality of conflict. Confucius once observed that it is not poverty itself which leads to the contributions to technological progress.

${ }^{26}$ This, judging by the fact that their fathers were farmers, low-skilled workers, or were neither members of the elite nor had a declared occupation. Calculated from Khan (2008), Table 3. The table precludes calculating the percent for Britain separately. See also Khan (2005).

${ }^{27}$ Charlesworth (1983) presents rural protest in Britain from 1548 to 1900 . Protests were particularly likely when food prices were high. He notes that, in Lowland England, "by the second decade of the seventeenth century ... lords were successful in ... sweeping away ... tenantry to make way for the large leasehold farm ... through the poor law, the attack on alehouses, the quarter session and the church court" (pp. 16-18). Patriquin (2006) notes that "it is striking that a profound recasting of class relations in England, one which left most people bereft of property and control over their lives, occurred without inducing a protracted and violent revolution" (p. 223). 
disaster [of class warfare], but rather inequality. Now, the implementation of the lineage system is designed to stimulate the basic human impetus to share foodstuffs on the basis of seasonal need, and to foster the collective husbanding of resources to smooth over good and bad years. [When the people adhere to this properly] there will be no need to rely upon government action to care for the destitute, the orphaned, and the ill. When such principles of sharing so as to eliminate poverty are observed, how can resources fail to be adequate? It was for this reason above all that the ancient rulers instituted the lineage system." (Rowe 1998, p. 383).

Although the Chinese and English risk-sharing institutions emerged to fulfill the same functions, they had different forms due to distinct cultural and institutional elements. Specifically, the English society did not have large, kin-based units implying that a lineagebased institution was too costly, if not impossible, for the state to create. The state turned to the pre-existing, self-governed parishes to provide poor relief. In China, however, lineages prevailed and the state's administration was designed to interact with large kinbased social structures and not their individual members. Creating a state-based poor relief system was too costly given the alternative of relying on lineages. Because their growth implications were unforeseen, these risk-sharing institutions were not designed to promote growth. It is therefore appropriate to consider the forms of these risk-sharing institutions as exogenous while modeling their impact on growth.

\section{The Model}

We model the rate of productivity growth as a function of risk-sharing institutions. After presenting the model's basic structure, this section models the benchmark case of a market economy and continues by considering two risk-sharing institutions. The first is a statebased institution which complements the market through redistribution to the poor. And the second is a lineage-based institution under which economic agents are insured by their lineages and they employ the technology chosen by their elders and share the output.

\subsection{The Basics}

Consider the following OLG, full information model. There is a continuum of agents in $\left[0, \frac{1}{1-\lambda}\right]$ each of whom is young for two periods and is old for the rest of her life. An agent might die with probability $1-\lambda$ at the beginning of each period and an agent who dies is immediately replaced. ${ }^{28}$ An agent is a 'newly born' in his first period, a 'young adult' in

${ }^{28} \overline{\text { Our analysis abstracts from fertility issues }}$ in order to demonstrate that things do not depend on timedependent variables and changes in relative prices. This implies, however, that we have to ignore fertilityrelated facts. We agree that fertility issues are important, but our focus is on the effects of risk sharing institutions and we leave potential linkages between fertility and risk sharing for future work. Moreover, 
the second, and an 'elder' thereafter. Standard models let agents be young for only one period. Yet, the relevant choice in our model is next period's capital productivity, which is driven by the next-period utility function. If agents were young for only one period, we could not capture age-dependent risk preferences. ${ }^{29}$

Denote by $u^{y}$ the utility function of a young agent (either newly born or young adult), by $u^{o}$ the utility function of an old agent and by $\beta$ the discount factor. The utility functions are defined over income and are increasing, concave, (twice) continuously differentiable, satisfying the Inada conditions and having decreasing relative risk aversion (DRRA). ${ }^{30}$

Only newly born agents can produce and each one is endowed with one indivisible unit of labor which young agents can only use to operate their own plant. Production also requires capital. The per-period production function of each newly born's plant is:

$$
y=(A k)^{\alpha}
$$

where $A$ is capital productivity, $k$ is capital units, $A k$ is the units of effective capital and $\alpha<1$ is the capital share. At the end of her first period, a newly born agent divides her income between consumption and saving in the form of capital. Young adults and elderly agents rent their capital, consume and save. Capital depreciates at rate $\delta$ per period. A newly born is endowed with the previous period's average capital productivity and depreciated average capital level. ${ }^{31}$ This 'inheritance' creates inter-generational spillover effects in our fertility-free model. ${ }^{32}$

Each agent $i$ can use one of two technologies that affect her future idiosyncratic capital productivity, $A_{t+1}^{i}$. These technologies differ in their expected impact on future productivity of capital rather than current output. The first technology is low-risk, low-return

capping population growth in this manner biases the analysis against our argument.

${ }^{29}$ Alternatively, we could have changed the timing of moves and let agents first make their technological choices, then have the productivity realizations and finally let agents produce. But this would have implied that young agents had to make decisions before they were born.

${ }^{30}$ Specifically, the utility function for individual $i$ is given by:

$$
\begin{aligned}
U\left(C_{\tau}^{i, \tau}\right)= & \sum_{t=\{0,1\}} \sum_{s_{\tau+t} \in S} \pi\left(s_{\tau+t} \mid s_{\tau+t-1}\right)(\beta \lambda)^{t} u^{y}\left(c_{\tau+t}^{i, \tau}\left(s_{\tau+t}\right)\right) \\
& +\sum_{t>1} \sum_{s_{\tau+t} \in S} \pi\left(s_{\tau+t} \mid s_{\tau+t-1}\right)(\beta \lambda)^{t} u^{o}\left(c_{\tau+t}^{i, \tau}\left(s_{\tau+t}\right)\right)
\end{aligned}
$$

where $S$ is the space of states of the world, $s_{\tau+t}$ is the state of the world at time $\tau+t, \pi\left(s_{\tau+t} \mid s_{\tau+t-1}\right)$ is the conditional Markovian probability, $c_{\tau+t}^{i, \tau}$ is the consumption of agent $i$ of generation $\tau$ in period $\tau+t$ and $C_{\tau}^{i, \tau}=\left(c_{\tau+t}^{i, \tau}\left(s_{\tau+t}\right)\right)_{t=0}^{\infty}$ represents every possible consumption value for each state of the world conditional on survival.

${ }^{31}$ The analysis is robust to reasonable alternative specifications such as one in which a newly-born individual's initial capital equals that of someone she replaces.

${ }^{32}$ An alternative specification is that capital fully depreciates upon one's death and there is no intergenerational capital bequest. We simulated this model and our results remained qualitatively the same. This is because $\delta$ is already so large that the effect of the additional depreciation becomes of second order. 
$(L R)$ and the second is high-risk, high-return $(H R)$.

As noted above, this general specification is aimed as capturing, in reduced form, the complex relations between risk and reward in pursuing productivity-enhancing activities. One interpretation of this specification is that of a choice among known technologies that are more or less risky. Another is that of experimenting outside the known technological frontier. And yet another is making productivity-enhancing economic choices more generally. Instead of explicitly modeling each of these complex possibilities, we attempt to capture their common denominator in a parsimonious manner.

All individuals — including the young adults and the old — decide in every period whether or not to alter their technology in an attempt to upgrade their capital productivity. Thus, when newly-born agents rent capital on the market, rented capital comes coupled with a technology chosen by the owners of capital.

Formally, each technology $j$ is defined by its expected return (in terms of new knowledge), $\mu_{j}$, and its variance $\sigma_{j}^{2}$ where

$$
\begin{aligned}
\mu_{L R}<\mu_{H R} \\
\sigma_{L R}<\sigma_{H R}
\end{aligned}
$$

Productivity of agent $i$ 's capital next period, $A_{t+1}^{i}$, depends on her current productivity, $A_{t}^{i}$, the return on the technology she chooses, $\mu_{j}$, and an individual-level idiosyncratic shock, $\varepsilon_{t, j}^{i}$. Specifically, we assume that the logarithm of productivity follows a random walk with drift as in

$$
\log A_{t+1}^{i}=\log A_{t}^{i}+\mu_{j}+\varepsilon_{t, j}^{i}
$$

where the distribution of the idiosyncratic shock for technology $j$ is

$$
\varepsilon_{t, j}^{i} \sim F:\left\{F: F^{\sim}\left(0, \sigma_{j}^{2}\right)\right\} \text { where } j=L R, H R
$$

The main distinction between this set-up and the theoretical growth models on which we build is regarding the rate of productivity growth. In the latter, productivity growth is either exogenous, due to investment in acquiring existing knowledge rather then producing new knowledge, or depends positively on variables that are assumed to change over time, such as population. However, here, productivity growth is endogenous reflecting technologically feasible choices at the social and individual levels. 


\subsection{Risk-sharing: the Market, the State and the Lineage}

The rest of this section considers the growth implications of different risk-sharing institutions through their impact on risk-taking. Consistent with the historical records, we assume that there is no insurance market and recognize that risk-sharing institutions influence the allocation of both decision rights and income. Our specification enables comparing an individualistic economy with or without state-based insurance with an economy with a lineage-based insurance. ${ }^{33}$ In the individualist society, labor and capital are allocated by market forces, each agent chooses a technology for her capital, and has no insurance unless provided by the state. In the lineage-based society, labor and capital are allocated within the lineage, elders choose a technology, and lineage members insure each other.

\subsubsection{Individualistic, Market Economy}

Consider a small open economy with a fixed, state independent rental rate of capital, $r$, and recall that a newly born agent produces by combining her labor with capital. ${ }^{34}$ The profit-maximizing level of effective capital units is therefore $A k=\left(\frac{\alpha}{r}\right)^{\frac{1}{1-\alpha}}$. Although all newly born agents have the same endowment, denote, for ease of exposition, the capital productivity and capital of a newly born agent $i$ born at time $t$ by $A_{t}^{i}$ and $k_{t}^{i}$, respectively. If a newly born is endowed with less than the optimal units of effective capital, $\left(\frac{\alpha}{r}\right)^{\frac{1}{1-\alpha}}$, she rents $A_{t} k_{t}$ units on the market and otherwise rents her excess capital in the market. The maximization problem for the newly born is $\max _{A_{t} k_{t}}\left(A_{t} k_{t}+A_{t}^{i} k_{t}^{i}\right)^{\alpha}-r A_{t} k_{t}$ implying the profit function of newly born agents in period $t$ is $\pi_{t}\left(A_{t}^{i}, k_{t}^{i}, r\right)=(1-\alpha)\left(\frac{\alpha}{r}\right)^{\frac{\alpha}{1-\alpha}}+r A_{t}^{i} k_{t}^{i}$ which is continuous and linearly increasing in the agent's initial capital $k_{t}^{i}$ and capital productivity $A_{t}^{i}$.

We can now turn to the inter-temporal problem of saving and technological choices. Given the agent's stock of capital and her productivity at the beginning of a period, she chooses a technology and how much to save. Recall that the capital productivity of each young adult and elder can differ due to individual-specific past outcomes. For simplicity, however, we present the optimization problem of an agent $i$ of cohort $k$ at time $t$. Denote by $J_{k, t}^{i}$ and $k_{t+1}^{i}$ the technological and saving decisions, respectively, of agent $i^{\prime} s$ cohort $k=1,2,3$ (a newly born, young adult and elderly respectively) in period $t$ (Note that $k_{t+1}^{i}$ equals her net capital plus saving at the end of period $t$.) Denote by $V_{k, t}^{i,}$ the value functions of such an agent. The dynamic programming problems are (using superscript $m$ to denote a market economy):

\footnotetext{
${ }^{33}$ Markets prevailed in pre-modern China, of course, but our focus is on the non-market relations among members of lineages.

${ }^{34}$ We keep the interest rate constant and exogenous to have a parsimonus model.
} 


$$
\begin{aligned}
V_{1, t}^{i, m}\left(A_{t}^{i}, k_{t}^{i}\right)=\max _{k_{t+1}, J_{1, t}^{i}} & u^{y}\left(\pi_{t}\left(A_{t}^{i}, k_{t}^{i}, r\right)-\left(k_{t+1}^{i}-(1-\delta) k_{t}^{i}\right)\right) \\
+\beta \lambda E\left[V_{2, t+1}^{i, m}\left(A_{t+1}^{i}, k_{t+1}^{i}\right) \mid A_{t}^{i}, J_{1, t}^{i}\right] & \\
V_{2, t}^{i, m}\left(A_{t}^{i}, k_{t}^{i}\right)=\max _{k_{t+1}, J_{2, t}^{i}} & u^{y}\left(r A_{t}^{i} k_{t}^{i}-\left(k_{t+1}^{i}-(1-\delta) k_{t}^{i}\right)\right) \\
+ & \beta \lambda E\left[V_{3, t+1}^{i, m}\left(A_{t+1}^{i}, k_{t+1}^{i}\right) \mid A_{t}^{i}, J_{2, t}^{i}\right] \\
V_{3, t}^{i, m}\left(A_{t}^{i}, k_{t}^{i}\right)=\max _{k_{t+1}, J_{3, t}^{i}} & u^{o}\left(r A_{t}^{i} k_{t}^{i}-\left(k_{t+1}^{i}-(1-\delta) k_{t}^{i}\right)\right) \\
+ & \beta \lambda E\left[V_{3, t+1}^{i, m}\left(A_{t+1}^{i}, k_{t+1}^{i}\right) \mid A_{t}^{i}, J_{3, t}^{i}\right]
\end{aligned}
$$

Decreasing relative risk aversion implies that sufficiently poor agents (those with low $A_{t}^{i} k_{t}^{i}$ ) adopt the $L R$ technology while sufficiently wealthy agents adopt the $H R$ technology. If there are initially sufficiently many poor agents, the average productivity of capital is low enough to make the $L R$ technology optimal for subsequent generations as well. If, however, there are initially sufficiently many wealthy agents who adopt the $H R$ technology, their choice has a positive inter-temporal spill-over effect; it increases the initial capital productivity of the newly born. This process of higher capital productivity reinforces itself and eventually every agent employs the risky technology. Our model thereby captures that technological choices have an external effect on productivity growth and either $L R$ or $H R$ technologies can perpetuate in equilibrium. ${ }^{35}$

The $H R$ technology Pareto dominates the $L R$ technology because shocks are agent specific and there is no aggregate uncertainty. ${ }^{36}$ It is Pareto optimal for all agents to use the $H R$ technology and share the output, thereby gaining from its positive intertemporal spillover effects. Risk-sharing institutions can therefore determine whether an economy remains in a $L R$ technology equilibrium or exhibits a transition to $H R$ technology equilibrium. In our model, a society can remain trapped in a low-growth equilibrium in the absence of an appropriate risk-sharing institution. If a risk-sharing institution is introduced, however, a larger fraction of the agents adopt the $H R$ technology and the increase

${ }^{35}$ Similarly, increasing returns to scale in the endogenous growth literature implies that higher income per capita leads to higher productivity levels, which itself increases income per capita and reinforces growth (e.g., Romer, 1986).

${ }^{36}$ For a proof, see Kocherlakota (1996) or Ligon, Tomas and Worral (2000). Since the endowment is state invariant in the economy and there is perfect risk sharing, agents will have constant consumption across states. Since total endowment is larger with the high-risk, high-return technology, agents will have a higher state-invariant consumption with the latter technology. 
in wealth can reinforce the adoption of the risky technology, up to the point where all agents utilize the $H R$ technology.

\subsubsection{State-based Insurance: the Old Poor Law}

Regardless of the social institutions it involved - be it state- or clan-based — relief to the poor could have distorted technological choices and the allocations of capital and labor if it had to be financed through taxes on the factors of production. The Old Poor Law, however, was financed by a tax on land. Taxing a fixed factor acts as a quasi lump-sum tax and it is therefore reasonable that distortions were relatively small. The evidence confirms that this was the case. ${ }^{37}$ Accordingly, we ignore the issue of financing (and its distortionary effect) to more clearly capture the Poor Law's impact on risk-taking rather than wealth redistribution. Similarly, those who paid or administered the tax had neither legal nor customary rights to influence others' technological choices.

On this basis, we assume that the Poor Law reduced the variance of the individual-level technological shocks as a means of mitigating appropriation risk. ${ }^{38}$ Specifically, denote the standard deviation of the individual level idiosyncratic shock under the Poor Law by $\sigma_{j, P L}^{2}, j=L R, H R$ and assume that:

$$
\varepsilon_{t, j}^{P L \sim} F_{P L} \text { with }\left\{F_{P L}: F_{P L} \sim\left(0, \sigma_{j, P L}^{2}\right)\right\}
$$

$$
\text { with } \sigma_{j, P L}^{2}<\sigma_{j}^{2}
$$

The Poor Law reduces risk and therefore the capital productivity levels above which agents adopt the risky technology. Formally, denote these thresholds of capital productivity levels in the market economy by $\left(\underline{A_{y}^{m}}, \underline{A_{o}^{m}}\right)$ for the newly born and the rest of the

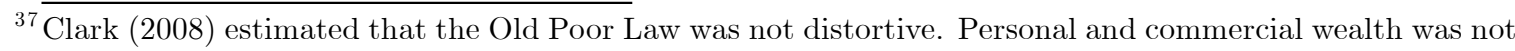
taxed. To the extent that the Poor Law thereby led to an allocation of more resources toward commerce and industry, it had an additional favorable impact on industrialization.

${ }^{38}$ We discuss the mechanism through which social insurance reduced appropriation risk in subsection 3.2.4 below. And we present an extension of our benchmark model that incorporates the adoption of social insurance in response to the threat of appropriation in Appendix B.

Another way to model the Poor Law is to truncate shocks below a certain threshold:

$$
\begin{gathered}
\varepsilon_{t, j}^{P L} F_{P L} \text { with }\left\{F_{P L}: F_{P L} \sim\left(0, \sigma_{j}^{2}\right) \text { and } \sup _{F}\left[-\iota_{P L}, \iota\right]\right\} \\
\text { where }-\iota_{P L}>-\iota, F\left(-\iota_{P L}\right)>0 \text { and } F_{P L}(x)=F(x) \forall x>-\iota_{P L}
\end{gathered}
$$

Since $E\left(\varepsilon_{t, j}^{P L}\right)>0$, this modeling of the Poor Law implies both a change in the risk structure and wealth. To keep the introduction of the Poor Law wealth neutral, we prefer modeling it as a reduction in the volatility of the shocks. 
agents respectively before the Poor Law, and by $\left(\underline{A_{y}^{P L}}, \underline{A_{o}^{P L}}\right)$ after the Poor Law. The reduction in risk implies that $A_{y}^{P L}<A_{y}^{m}, \underline{A_{o}^{P L}}<\underline{A_{o}^{m}} .{ }^{39}$ See proof in Appendix A.

By reducing the threshold levels above which agents adopt the risky technology, the Poor Law can initiate a transition that otherwise would not have taken hold. The simulation below lends support to the argument that the Old Poor Law had such impact. Before turning to the simulation, however, we address the comparative question: couldn't an equivalent lineage-based insurance system have been similarly effective in initiating a transition? As it was practiced in China, we find that the answer is 'no'.

\subsubsection{Social Insurance: The Lineage}

The distinct assignment of decision rights were associated with the Chinese lineage-based institution and the English Poor Law. Under lineage-based insurance, elders had more decision rights over technological choices than they had under the English Poor Law. The following extension of the model captures this notion.

A lineage, $\Gamma$, is a finite group of agents of different generations that merge their endowments, share the output they produce and communally decide which technology to use. Accordingly, we assume that the elders determine the technological choice and the capital accumulation within each lineage. Formally, the evolution of the capital stock for the average lineage is $k_{t+1}^{\Gamma}=k_{t}^{\Gamma}(1-\delta)+h_{t}^{\Gamma}$ where $k_{t}^{\Gamma}=\sum_{i \in \Gamma} k_{t}^{i}$ and $h_{t}^{\Gamma}$ is investment at time $t$. Since each lineage has a finite number of agents, even initially identical lineages will subsequently differ in their per-period mortality and membership. We therefore model the dynamics of an average lineage, whose demographics are identical to that of the population as a whole. The average lineage is composed of $\frac{N}{1-\lambda}$ agents. For each newly born agent, there are $\lambda$ young adults and $\frac{\lambda^{2}}{1-\lambda}$ elderly agents implying an expected number of $\frac{N}{1-\lambda}$ agents.

Capital and labor are matched within the lineage and output is divided, without loss of generality, equally among members. Each member obtains $\frac{1-\lambda}{N}$ of the total production. To maintain comparability with the individualistic society and to capture insurance provided by the lineage, we assume that the capital of each lineage's member is still subject to individual-level idiosyncratic shocks. The variance of the productivity shock that such a lineage faces is $\frac{N}{1-\lambda}$ times smaller than the variance of any given technology. ${ }^{40}$ Lineages

${ }^{39} \overline{\text { It is sufficient to focus on the newly borns }}$ and the elders because the threshold for the young adult and the elderly are the same. The choice of the technological regime impacts next period utility, with both the current young adults and elder agents having the same preferences.

${ }^{40}$ The stock of units of effective capital per lineage is $\left(A_{t}^{\Gamma} k_{t}^{\Gamma}\right)=\sum_{i \in \Gamma} A_{t}^{i} K_{t}^{i}$. For sake of simplicity we assume that, for each newly born, there are $\sum_{i \in \Gamma} \frac{A_{t}^{i} K_{t}^{i}}{N}$ units of effective capital. Note that since the production 
provide insurance.

Insurance provided by the lineage, everything else being equal, makes a transition more likely. Lineage-based insurance, similar to the Poor Law reduces risk and therefore the capital productivity levels above which agents adopt the risky technology. Formally, denote these thresholds, when there is insurance, by $\left(\underline{A_{y}}, \underline{A_{o}^{\Gamma}}\right)$. Everything else being equal, the lineage-based insurance might be as effective in promoting risk taking as the Poor Law.

But not everything was equal and, in the case of China, elders had more decision rights than other members. Accordingly, we assume that the elders determine the choice of technology and the capital accumulation within each lineage. Hence, only the problem of the elders matters for the derivation of a clans optimal policies. The value functions for the newly born and the young adults are determined by the elders' investment choice and there is full insurance - equal consumption, at least for each cohort — within the clan. ${ }^{41}$ The elders' decision can be summarized in recursive form as before:

$$
\begin{aligned}
V_{3, t}^{\Gamma}\left(A_{t}^{\Gamma}, k_{t}^{\Gamma}\right)=\max _{k_{t+1}^{\Gamma}, J_{3, t}^{\Gamma}} & u^{o}\left((1-\lambda)\left(\left(A_{t}^{\Gamma} k_{t}^{\Gamma}\right)^{\alpha}-\left(k_{t+1}^{\Gamma}-(1-\delta) k_{t}^{\Gamma}\right)\right)\right) \\
& +\beta \lambda E\left[V_{3, t+1}^{\Gamma}\left(A_{t+1}^{\Gamma}, k_{t+1}^{\Gamma}\right) \mid A_{t}^{i}, J_{3, t}^{\Gamma}\right]
\end{aligned}
$$

Since the elders are more risk averse than the young, the elders would choose, ceteris paribus, the $L R$ technology in situations in which the newly-born agents would be indifferent between the $H R$ and $L R$ technologies. In particular, different choices are likely in 'intermediate' levels of capital productivity. (See Appendix A.) Two opposite forces emerge in the lineage-based society. On the one hand, insurance within the lineage fosters risk taking. On the other hand, the elders' higher risk aversion discourages risk taking. Which force would dominate and whether the lineage-based insurance promotes growth is an empirical matter.

function is decreasing in units of effective capital, dividing the units of effective capital evenly across the newly born agents is the most efficient allocation (and bodes well for our analysis focusing on the average lineage). Also note that the lineage's variance is $N /(1-\lambda)$ times smaller than an individual shock only if shocks are indpendent across lineage members and also if all members have the same units of effective capital. We will take the most comprehensive case of insurance in the lineage and then compare it to the individualistic, market economy.

${ }^{41}$ All elders will make the same choice given that each considers the clan's total effective capital. 


\subsubsection{The Emergence of Social Insurance}

While our main theme in this paper revolves around the differences between state-based and clan-based social insurance systems in China and England, a more fundamental issue involves why social insurance schemes came to be adopted in both countries in the first place.

The political economy literature has long emphasized the risk of extralegal appropriation and the threat of violent conflict as important motives for redistributive policies that were supported by the political and economic elite. ${ }^{42}$ Indeed, as we have alluded to in subsection 2.3 above, there is some historical evidence that such concerns played a role in the adoption of the Old Poor Law in England and the emergence of the clan-based social insurance system in China.

In Appendix B, we present a simple extension of our model which illustrates the potential role of appropriation risk in the advent of a state-based social insurance program. In particular, we illustrate there that the risk of extralegal appropriation for the wealthy individuals is highest in an economy with high income variance. While we chose not to elaborate on this point further below, with slight modifications, the extension in Appendix $\mathrm{B}$ could be embedded in our basic framework to motivate the rise of the clan-based system in China as well.

\section{Simulations}

The absence of data prevents us from conducting an empirical analysis. In the context of our model, however, we can use simulation analysis to ask the following questions:

1. Could the risk of appropriation have resulted in the emergence of social insurance structures, such as the English Old Poor Law and Chinese clan-based networks?

2. Could differences in decision making rights inherent in these social structures have affected risk-taking in a quantitatively significant way?

3. Could the resulting differences in risk-taking account for England's transition and China's stagnation?

Our simulation suggests an affirmative answer to all three questions.

The first part of this section discusses our calibration strategy. To make the simulation meaningful, we resort to historical evidence in choosing our parameters wherever possible.

\footnotetext{
${ }^{42}$ For some work on the links between production, appropriation and allocation of resources to conflict, see Hirshleifer (1991), Grossman (1994) and Grossman and Iyigun (1995). For the role of class conflict on the enactment of redistributive policies, refer to Grossman (1994) and Acemoglu and Robinson (2000).
} 
In the absence of such evidence, we set the parameters, when reasonable, to values that are standard in the literature. We calibrate the remaining parameters to render the model consistent with the observed long-run growth trajectory prior to the transition in England.

The calibrated model is then used in our simulation analyses. Specifically, we first simulate both economies with relatively constant levels of consumption per capita. This captures the situation in China and England prior to 1600. A simulation then examines the impact of an introduction of a state-based risk-sharing institution assuming that it provides the same level of risk-sharing as clan-based insurance. This simulation thus captures the impact of institutional forms and not functions, namely, the difference in risk-taking entailed by the distinct decision rights that were inherent in these institutions. We then evaluate whether the Poor Law could have tilted the balance of risk-taking to initiate a transition. On that basis, we proceed to examine how much more insurance the lineage system would have needed to spur a transition to sustained growth.

Finally, we investigate the role of income inequality on the adoption of a social insurance system - specifically, that of the Old Poor Law. Thus, for these last set of simulations, we turn to the extended version of our model with appropriation risk, which is in Appendix B.

\subsection{Parameter Choices}

This subsection presents some motivation for our choice of parameter values. The parameters relate to demographics, preferences, technologies and the exogenous rental price of capital. Table 1 summarizes the parameters chosen for our baseline simulations.

\subsubsection{Demographic Structure}

Each period lasts for twenty years. Agents are referred to as newly born in the 0-19 cohort, young adults in the 20-39 cohort and elderly for the rest of their lives. Agents die and exit the model with a per-period probability, $1-\lambda$, of 0.5 . This is consistent with the high rate of pre-modern mortality before adulthood and implies that an agent's expected working life is thirty years. Given that, as late as the early 19th century, life expectancy at birth was about 40 years, this seems to be a sensible assumption. ${ }^{43}$ We assume that young agents are born with the average productivity and the average capital level within their respective societies.

\footnotetext{
${ }^{43}$ In early nineteenth century China (the Yangzi Delta), male life expectancy at 15 was between 30 to 54 years (Liu, Cuirong, 1992 cited by Brenner and Isett, 2002). In our model, the probability of being older than 100 years is $3.125 \%$. This is clearly unrealistic, but keeping an unconditional death probability simplifies the model and keeps the issue of fertility as silent as possible.
} 


\subsubsection{Preferences}

As explained in detail in the previous section, our mechanism hinges on the agents' decreasing appetite for risk at lower levels of wealth and old age. One way to ensure that is with a utility function that exhibits DRRA and higher risk aversion for the elders. We choose a standard CES utility function that is augmented by a minimum level of (subsistence) consumption that varies by age. The risk aversion parameter, $\omega$, is set to 5 which is within the range of risk aversion coefficients used in macroeconomics. We assume Stone-Geary preferences with a higher minimum consumption for the old to endogenize differences in risk preferences. Specifically, we use the following utility function where the exponent $a=\{y, o\}$ signifies the agent's age:

$$
u^{a}=\frac{\left(c-\bar{c}^{a}\right)^{1-\omega}-1}{1-\omega}
$$

The coefficient of relative risk aversion $R$ varies by age and the agent's level of consumption.

$$
R^{a}=\omega\left(\frac{c}{c-\bar{c}^{a}}\right)
$$

We assume that there is no minimum consumption requirement for the young, hence $\bar{c}^{y}=0$. The minimum consumption requirement for the elderly is set at a higher value of $\bar{c}^{o}=0.06$. This specification leads to a moderate difference in risk aversion between the young and the old when the steady state consumption per capita is the same across societies. (Namely, before the poor law is established.) In that steady state, the risk aversion coefficient for the young is 5 and only $11.3 \%$ higher for the elders, at 5.58 .

As a side note, we have already stated in footnote 11 on page 4 that there could be economic fundamentals behind individuals getting more risk averse in old age. In that vein, an alternative to the specification in (7) is a CES utility function with habit formation in consumption, where

$$
u_{t}^{a}=\frac{\left(c_{t}-c_{t-1}\right)^{1-\omega}-1}{1-\omega}
$$

with the coefficient of risk aversion now being equal to

$$
R_{t}^{a}=\omega\left(\frac{c_{t}}{c_{t}-c_{t-1}}\right)
$$

As long as $r \beta \lambda>1$, the optimal consumption path would be upward sloping, making individuals relatively more risk averse with age.

In the simulations discussed below, we shall employ the specification in (7), although other simulations in which we use the utility in (8) yielded qualitatively similar results. 


\subsubsection{Technological Choices}

As set in equation (3.a), the logarithm of $A$ follows a random walk with drift. For each technology, we thus have to calibrate the drift term as well as the variance of its innovations. For the $L R$ technology, the average growth rate is set to zero, $\mu_{L R}=0$, to reflect the absence of sustained growth before the Industrial Revolution. In the early stages of the English Industrial Revolution (roughly from 1780 to 1820), the annual income per capita growth rate increases to a value just below 0.5\% (Maddison 1991). Accordingly, we assume that the $H R$ technology has a per-period return of $\mu_{H R}=10.5 \%$ which implies a $0.5 \%$ return a year.

The innovations to $A$ are assumed to be uncorrelated both across agents and time and normally distributed with a mean of zero. The standard deviation of innovations for the low-risk technology is set at a low value of 0.015 . The standard deviation of innovations for the $H R$ technology is then set at a value of 0.19 which implies slightly more than a tenfold increase. This value is chosen to reproduce the historical evidence of stagnant growth in the baseline case and a take-off in England after the introduction of state-based insurance through the Poor Law.

Under the system of clan based insurance in China, the standard deviation of innovations can be directly linked to the size of the clan which determines the number of agents who pool resources and thus partially insure each other. There is some historical evidence on the size of a typical clan. While a stem family had, on average, ten members with about six working adults (Liu, 1959, pp. 2-3), a clan could reach a size of more than 1000 adults. Fei and Liu (1982, p. 387) report a 'critical maximum' size of 1400 adults and note that clans disintegrated beyond that size. Their effectiveness in assisting their poor members, most likely, declined long before reaching their maximum size for two reasons. First, effectiveness declined as members of the clan lived further away from each other. Second, clans usually supported their needy members by using the income from a trust set up for this purpose early in the clan's history. As the clan grew in size, the support per-pauper was likely to decline. In the same book, Fei and Liu report numbers for a typical clan with an average of 144 male adults. ${ }^{44}$ In the context of our model, this implies a clan size of 288 male members which yields a value of 144 for the parameter $N$ which denotes the number of newly born male members. Under our assumptions, the standard deviation of shocks to the lineage is given by $\sigma^{C H}=\sigma N^{-0.5}(1-\lambda)^{0.5} \cdot{ }^{45}$

Turning to the case of England, the Poor Law itself provides partial insurance against

\footnotetext{
${ }^{44}$ Of the clan's 481 members, $60 \%$ were adults. Hence, we are left with 144 male adults.

${ }^{45}$ We have performed a comparative statics analysis where we increase the number of agents per lineage. Not surprisingly, the more agents are present in the lineage, the more inclined the lineage is to engage in the risky technology. This matches the anecdotal evidence of the Tong and Song dynasties, where lineages were widely extended as well as economic prosperity.
} 
those shocks. This is captured by the parameter $\varphi_{P L}$ that determines the standard deviation of innovations under the Poor Law as a share of the standard deviation in the baseline case such that $\sigma_{P L}=\varphi_{P L} \sigma$. As we are lacking a strong empirical prior on how to calibrate this parameter, we set it at a value that exactly equalizes the variance of innovations in China to those in England under the Poor Law. In that sense, we calibrate the model such that both methods of insurance alleviate the shocks agents are confronted with by the same degree. To achieve this end, we set this parameter at 1/17.

The remaining parameters are chosen as follows: We set the annual discount factor to 0.975 which implies a discount factor in the model, $\beta$, of 0.603 per period. The capital share $\alpha$ is $1 / 3$ and the depreciation rate $\delta$ is set to 0.543 , implying a $3 \%$ annual depreciation. Based on the historical interest rates reported in Homer and Sylla (1998), we set the interest rate $r$ to an annual value of $4.5 \%$ which yields a $141 \%$ return every twenty years.

\subsection{Simulations}

\subsubsection{Setup of Simulation Experiment}

The problem of the elderly can be solved as a standard infinite horizon consumptionsaving problem that is extended by the endogenous choice of technology. ${ }^{46}$ Given the value function of the elderly, we can solve the model backwards. The problem of the young adults and newly born can both be solved in a single iteration where each cohort uses the following cohort's value function as a continuation value. This allows us to derive optimal policies for all age groups. In the case of China, the problem is even easier and reduces to solving the problem of the elderly as they are the ones making decisions for the whole clan.

With the optimal policies at hand, we can simulate an economy inhabited by a large number of agents. ${ }^{47}$ As outlined above, every agent who dies is replaced by a newly born agent who enters the model with the average capital stock and productivity as the surviving agents in the economy or the clan, respectively. The initial capital stock and productivity values are chosen to prevent $A_{t}^{i}$ from becoming negative. This economy is simulated for a large number of periods until it reaches its stationary distribution.

We then model the exogenous introduction of the Poor Law as a reduction in the

${ }^{46} \overline{\text { We use value-function iteration on a grid }}$ for capital and productivity. The process for productivity is approximated as a finite state Markov process using a variant of the approximation method developed by Tauchen (1986) and Tauchen and Hussey (1991). We use a very wide grid to prevent artificial mean reversion at the bounds of the grid. In additon, we approximate the value function outside the grid for productivity using a spline approximation.

${ }^{47}$ As we close the model with an exogenously assumed interest rate, the number of agents in each generation does not affect the results other than to provide smoothing across simulations. The graphs depicted in this paper come from a simulation that uses 10,000 agents. 
variance of innovations to the productivity process. In terms of the simulation, this is achieved by simply using the appropriate policy functions and transition matrix. ${ }^{48}$

Finally, as in Appendix B, we incorporate appropriation into our model in order to simulate the endogenous adoption of the Old Poor Law in England.

\subsubsection{Simulation Results}

In every period, agents choose between the $L R$ and $H R$ technologies. The optimal choices can be represented graphically as shaded areas in the $(A, k)$-space. Figures 1 and 2 , for instance, show the combinations of productivity and capital for which the elderly and the newly born choose the different technologies, respectively. The shaded area at the lower left represents the adoption of the $L R$ technology while the white area denotes the adoption of the $H R$ technology. The figures illustrate that agents with a relatively low capital stock and a low level of productivity are less likely to choose the $H R$ technology despite its higher expected growth rate. Moreover, when comparing Figures 1 and 2, it becomes clear that the elderly are less willing to take risks. This is simply a result of their larger risk aversion implied by the preference specification.

The introduction of the Poor Law reduces the dispersion of shocks under both technological choices. Figures 3 and 4 illustrate that both the elderly and the newly born are willing to take more risks - the shaded area of $L R$ choices is much smaller and only applies for very low levels of capital and productivity.

In the lineage society, decisions are made by the elderly alone. Figure 5 depicts their choices, again in the $(A, k)$-space. While the partial insurance within the clan yields significantly larger risk taking than in the market society, the effect is not as strong as under the Poor Law.

The time-series simulation supports the conjecture that risk-sharing institutions played a pivotal role in England's transition and China's relative lack of economic growth. Before the introduction of the Poor Law, there is no risk sharing in the market economy. Consequently, agents opt for the low-risk technology and the economy is literally stagnant. When the Poor Law is introduced, the thresholds to engage in riskier activities fall and there is an instantaneous spike in the fraction of the population that chooses the $H R$ technology as the benefit of a higher expected growth rate is no longer offset by the larger dispersion of shocks. This generates income per capita growth that fosters further risk taking. A transition transpires until every agent uses the $H R$ technology.

\footnotetext{
${ }^{48}$ Alternatively, one could assume that the Poor Law is introduced gradually. There is evidence that the insurance provided by the Poor Law reached different parishes at different times reaching all of England only around 1700. In terms of our model, the only difference would be a smoother transition to the growth path.
} 
This process can be observed in Figure 6 which plots the share of agents in the market society that employ the $H R$ technology. After the Poor Law introduction, this share jumps up to just below $50 \%$ before increasing slowly toward full adoption. In the lineage economy, by contrast, risk-sharing within the clan motivates some of the relatively more risk-averse elders to chose the $H R$ technology, but their number is too low to initiate a sustained transition. Hence, there is no major shift toward using the $H R$ technology.

The transition to a dynamic growing economy after the Poor Law introduction can be studied further in Figures 7 through 10. Average productivity growth takes off after the adoption of the Poor Law as more and more agents choose the $H R$ technology. Investment, however, drops at first as there is less need to insure against bad realizations of productivity growth. This is depicted in Figure 8. As productivity reaches higher and higher levels, however, investment picks up too. Figure 9 illustrates the resulting development of the capital stock and Figure 10 plots consumption which increases immediately following the Poor Law's introduction.

These results remain wholly intact when we extend our baseline model to incorporate appropriation risk and the commensurate endogenous adoption of a social insurance system. For heuristic purposes, consider the English case where, according to our framework, historical dynamics dictated the adoption of state-based social insurance when such a system was socially or politically desirable.

First, take the case in which the Old Poor Law is not in effect, and some individuals can engage in extralegal means to appropriate others' resources. Figures 11 and 12 draw the analogs of Figures 1 and 2 when there is some degree of appropriation in the economy. Both among the young and the old, we see that those with the least amount of efficiency units of capital engage in appropriation. However, there are relatively more young than old who engage in appropriation (instead of production) because the young have fewer resources, which lowers their appropriation opportunity cost. The next two figures replicate 11 and 12 with the exception that the appropriation productivity parameter, $B$, is now set at a higher level. As shown, and not too surprisingly, when $B$ is set at 6 instead of .1, more young and old individuals engage in appropriation. As a result, the threshold combinations of capital and technology for the adoption of the high-risk technology rises. Hence, appropriation creates both direct and indirect adverse effects on the economy: not only does it take more capital and technology to decide to engage in productive activities, but it takes even more to adopt the high-risk technology when some resources could be lost to extralegal appropriation.

In Figures 15 and 16, we depict what happens with the Old Poor Law in effect and the appropriation technology parameter, $B$, set at its upper bound of $6 .{ }^{49}$ As shown, the

\footnotetext{
${ }_{49}^{4}$ As we shall discuss subsequently, it is socially optimal to adopt the Old Poor Law if $B$ exceeds 1.5 and
} 
Old Poor Law not only eliminates appropriation, but also encourages more individuals to adopt the high-risk technology, both among the old and the young.

Of course, the adoption of a social insurance scheme based on income transfers has costs to society. Thus, its social net benefit depends on the degree of income inequality in the economy and the effectiveness of extra-legal appropriation. In our final set of simulations, we investigated the combinations of parameter values and state variables that socially and dynamically justified the adoption of social insurance.

Figure 17 reports the outcome of one such exercise in which the degree of income inequality is relatively low. In the figure, we plot average social welfare as a function of the parameter of technology of appropriation, $B$, and with all other parameters set according to Table 1. As shown, when no social insurance program exists, social welfare declines as the return to appropriation rises with increases in $B$. With the Old Poor Law in effect, there is no appropriation and average welfare remains independent of $B$, although the amount of income transfers from the rich to the poor rises with $B$. Most importantly, however, is the fact that $B$ needs to be sufficiently high (i.e., in excess of 1.6 or 15 out of 50 in our grid scale) for the Old Poor Law to be socially optimal. And, although not shown, higher income inequality would also make it more likely that the Old Poor Law is adopted, even when $B$ is below the threshold shown, which is 1.6.

\section{Supporting Historical Observations}

The comparative technological history of China and England is puzzling. China was ahead of England around 1000 CE but subsequently fell behind. During the Song dynasty (960-1279 CE), China was the world's technological leader. It "developed an amazing technological momentum, and moved, as far as these matters can be measured, at a rate as fast as or faster than Europe" (Mokyr 1990, p. 208). Yet, shortly after the fall of the Song, technological development slowed and China became, relatively speaking, technologically stagnant (ibid, p. 219). England became the leader. This reversal of fortune is inconsistent with existing endogenous growth models. Our conjecture is consistent with both.

First, consider China. We argue that two factors determined the impact of its lineagebased institutions on growth. Intra-lineage insurance encouraged risk-taking while control by the risk-averse elders discouraged risk-taking. This implies more (less) technological progress when lineages provides more (less) insurance, when elders are less (more) powerful, and when there is no state-provided insurance. Consistent with these predictions, there was more insurance and innovations in China early on when communal families (in which output was equally shared) predominated. The clans that prevailed during subseincome inequality is relatively high. 
quent dynasties only provided poor relief and thus less insurance (subsection 2.3). Elders also had less legal authority during the Song dynasty than later. Under the Song, a parent who killed an unfilial son was subject to less punishment compared to other murders. As severe as this law may seem, it was mild compared to the law in later dynasties under which it was not a crime for a father to kill an unfilial son! (Hamilton, 1990, p. 86). Clearly, disobeying one's father in post-Song China was a dangerous proposition.

Finally, the Song was the only post-1000 CE dynasty to have had a substantial statebased, risk-sharing institutions. Wang Anshi, a prominent Song minister and reformer, asserted that the state was responsible for providing the poor. Under his direction, the state instituted pensions for the needy. (Ebrey, Walthall, and Palais, 2005). Later dynasties did not follow this example although, because clans were mainly rural, poor relief was sometimes provided in cities.

Prior to the seventeenth century, England was less innovative than China. Our analysis suggests the importance of China's effective risk-sharing institutions in causing this outcome. Following the introduction of the Poor Law in England during the seventeenth century, however, the intellectual and organizational basis of England's industrial revolution was formed (Mokyr, 2005). There was, in particular, a rise in the distribution and creation of new agricultural knowledge as measured by patents and technical manuals. Between 1550 and 1600, the number of patents was zero and the number of published farming technical manuals was 16. In the next 50 years the numbers increased to 28 and 43 respectively (Sullivan, 1984, Table 1). ${ }^{50}$ England's economic ascendancy had began in the seventeenth century (Nef, 1940; Clark, 2005). While real wage declined in the sixteenth century, they increased after 1601 and, by the 1740s wages were 67 percent higher than would have been predicted by the pre-1600 relations between population and real wages. ${ }^{51}$

If the Poor Law reduced risks, areas with better poor relief should have had higher rates of innovation and growth. Although in principle this is a testable proposition, unobservable variations over time and space preclude doing so. These variations includes parish-level politics, the endogenous level of poor reliefs expenditures, local and weather related economic conditions, the sequentiality and randomness of innovations, the employment implications of different innovations (e.g., drainage, economies of scale, new agricultural products and techniques, turnpike, and enclosure), and negative or positive inter-parish externalities. ${ }^{52}$ A positive correlation between poor relief and growth is sug-

\footnotetext{
${ }^{50}$ Sullivan conjectured that the increase reflects population growth. The rate of population growth, however was much lower.

${ }^{51}$ Allen (2001); Clark (2005).

${ }^{52}$ Boyer 1986, for example, found that, in the early 19th century, the higher per-capita expenditures on poor relief in the agricultural counties, compared to industrial ones, reflected differences in the local political power of labor-hiring farmers.
} 
gested, however, by a survey conducted by the Board of Trade in 1696. The survey reveals a "heavy expenditure [on poor relief], relative to population, in towns and industrial areas, suggesting that they had been first in the field" (Slack, 1990, p. 18).

Another puzzling observation is that during the Industrial Revolution, England did not stand out as particularly inventive. It was particularly good at adopting, adapting, and commercializing inventions made elsewhere. ${ }^{53}$ France, in contrast, was a particularly important source of inventions (Mokyr, 1990). This observation is consistent with our conjecture. England's risk-sharing institutions did not specifically reward inventors and its patent system was not particularly rewarding either (e.g., Khan, 2008). The Poor Law encouraged risk-taking in commercializing inventions by securing local landlords and industrialists from the social unrest that their innovative activities might have otherwise caused. France, which did not have a patent system during that period, was nevertheless inventive because inventors were rewarded by the Crown (Kremer, 1998). France's Poor Law system, however, was not as effective as England's (e.g., Solar, 1995, p. 7; Lindert, 2004 , p. 8) and innovations did not follow inventions.

Despite the differences in poor relief between England and the continent, the European states were in a better position to imitate England than China. They did not have lineages, elders had less power, and some state-based poor relief existed. As our analysis predicts, Europe's transition to the modern economy quickly followed England's, while China did not. Notably, the continental industrialization transpired in the context of creating the modern, state-based welfare system. (Lindert, 2004). At this point in the process of the rise of the modern economies, formal education became more important as a source of productivity growth (Easterlin, 1981).

\section{Conclusion}

In existing growth-theoretic models, the initial increase in the rate of productivity growth that causes transitions to a modern economy are due to either favorable realizations of random economic variables or a technological drift. This paper presents how institutional changes can initiate a transition by causing an endogenous technological drift. Analytically, our model considers the impact of distinct forms of risk-sharing institutions on risk-taking, new useful knowledge, and rates of technological change.

Historically, the paper focuses on risk-sharing institutions in pre-modern China and England. In both societies, such institutions were introduced for similar moral and political reasons. The forms of these institutions, however, were determined by pre-existing

\footnotetext{
${ }_{53}$ Mokyr (1990, 2002) highlights the importance of complementary factors such as an advanced machine tool industry. These, however, also reflect the growth in useful knowledge.
} 
cultural, social, and institutional features. Clans were a central component of China's social and cultural fabric and provided the state with such services as taxation and adjudication. It was optimal for the state to rely on clans also to provide social safety nets. The resulting clan-based, risk-sharing institutions contributed to the influence of the elders on economic decisions. The stronger influence of the relatively more risk-averse elders had a negative effect on risk-taking, new knowledge, and growth. Societies in which risk-sharing was provided by elder-dominated kinship groups were less likely to experience a transition to a modern economy. ${ }^{54}$

In England, during the same time, there were no large kinship groups and individualism prevailed. Non-kin based organizations, such as parishes provided the state with administrative services. It was optimal for the state to rely on parishes to provide insurance as made explicit in the Old Poor law of 1601. This risk-sharing institution did not shift decision power to the relatively more-risk averse elders. The Poor Law had the unintended consequence of fostering risk-taking, new useful knowledge, higher rate of productivity growth and the transition to the modern economy. It better insured the young thereby motivating risk-taking. Better insurance to the poor reduced the risk from social unrest that the wealthy faced when implementing new knowledge. ${ }^{55}$

The unintended consequences of the distinct forms of risk-sharing institutions in China and England suggests "why was England first" and why Europe, being culturally and socially similar to England, was second. Ironically, Europe's success seems not to have been due to foresight but an unintended consequence of its peculiar institutions. Our analysis supports the view that institutional distinctions - in functions and forms were central, rather than epiphenomenal, to transition to modern economies.

Transitions' institutional conditionality is a contested issue in economic history and growth theory. Economic historians have traditionally emphasized England's growthenhancing institutions, such as limited government, better labor markets, and a social environment conducive to innovations (e.g., North and Weingast, 1989; Mokyr, 1990, 1999, 2007; and Solar, 1995). More recent literature, however, has down-played institutions' role, claiming that intra- and inter-European institutional distinctions were insignificant on the eve of the Industrial Revolution (e.g., Craft 1977; Pomeranz, 2000; Clark, 2005).

Growth theory has similarly downplayed the importance of institutional distinctions

\footnotetext{
${ }^{54}$ Risk-sharing institutions might still be relevant in determining the rate of productivity growth. In contemporary Africa, for example, parents do not adopt Pareto-improving technologies that would have reduced their control over their children and hence the likelihood of old-age support (e.g., Hoff and Sen, 2005).

${ }^{55}$ The positive mortality and real wage trends ended one hundred and fifty years after the Old Poor Law was enacted. Real wages, for example, declined during the second half of the 18th century and rose again only in the 19th. The real world, unlike our model, exhibited urbanization, population growth, the Napoleonic wars, and industrialization that changed workers' bargaining power. See Crafts (1985); Steckel and Floud (1997); Weir (1997); Cinnirella (2008).
} 
and emphasized the importance of accidents in determining the historical sequence of transitions. The "Industrial Revolution transpired due to an exogenous increase in research productivity" (Kremer, 1990, p. 706). Institutions have been considered to impact, at most, the sequence of transitions but not the process leading to them. "Policy and institutions, by discouraging or preventing the invention and adoption of new ideas, might play an important role in determining when" industrialization transpires and "the fact that the industrial revolution happened first in England, ... rather than ... China ... is perhaps due to the institutions and policies in place in these two countries" (Hansen and Prescott, 2002, p. 1215; and see Galor, 2005, p. 178).

Our analysis suggests that institutions play a larger role in transitions determining whether or not transitions will transpire by influencing risk taking, technological development, and thus the rate of productivity growth. More generally, this paper reaffirms that it is possible and rewarding to build on the pioneering recent works in growth theory to better capture the complexity and diversity of growth processes. The functions and forms of non-market institutions, and the political, social and cultural factors that influence institutional selection matter. Incorporating institutions into unified growth theory has the promise of enhancing our understanding of the "change in human condition that the industrial revolution represents" (Lucas, 2002, p. 110). 


\section{Bibliography}

Abramitzky, R. 2008. "The Limits of Equality: Insights from the Israeli Kibbutz," 123:3, 1111-1159, Quarterly Journal of Economics.

Acemoglu, D. and J. A. Robinson. 2000. "Why Did the West Extend the Franchise? Democracy, Inequlaity and Growth in Historical Perpective," Quarterly Journal of Economics, 115, November, pp. 1167-1199.

Acemoglu, D., S. Johnson, and J. A. Robinson. 2001. "The Colonial Origins of Comparative Development: An Empirical Investigation." American Economic Review 91 (Dec.): 1369-1401.

Acemoglu, D., and F. Zilibotti. 1997. "Was Prometheus Unbound by Chance? Risk, Diversification, and Growth", Journal of Political Economy 105: 709-751.

Allen, R. (2001). The Great Divergence in European Wages and Prices from the Middle Ages to the First World War. Explorations in Economic History, 38, pp. 411-47.

Bates, R., A. Greif, and S. Singh. 2002. "Organizing Violence," Journal of Conflict Resolution, Vol. 46 No. 5, October, 599-628.

Broadberry, S. and B. Gupta. 2006, 'The Early Modern Great Divergence: Wages, Prices and Economic Development in Europe and Asia, 1500-1800', Economic History Review 59: 2-31.

Becker, G. S., K. M. Murphy, R. Tamura. 1990. "Human Capital, Fertility, and Economic Growth." The Journal of Political Economy, Vol. 98, No. 5(2), pp. S12.

Brenner, R. and C. Isett. 2002. "England's Divergence from China's Yangzi Delta: Property Relations, Microeconomics and Patterns of Development," The Journal of Asian Studies, 61(2) May): 609-662.

Brenner, R. 1987. "Agrarian Class Structure and Economic Development in Pre-Industrial Europe." In T.H. Aston and C.H.E. Philpin (eds), The Brenner Debate. Agrarian Class Structure and Economic Development in Pre-Industrial Europe. Cambridge: Cambridge University Press. Pp. 10-63.

Boyer, G. 1986. "The Old Poor Law and the Agricultural Labor Market in Southern England: An Empirical Analysis." Journal of Economic History, 46(1): 113-135.

Boyer, G. 1990. An Economic History of the English Poor Law, 1750-1850. Cambridge: Cambridge University Press.

Charlesworth, A. 1983. An Atlas of Rural Protest in Britain, 1548-1900. Philadelphia: University of Pennsylvania Press.

Chen, J. 1999. Chinese Law. Cambridge, MA: Kluwer Law International.

Cinnirella, F. 2008. Optimists or Pessimists? A Reconsideration of Nutritional Status In Britain, 1740-1865. European Review of Economic History, 12, 325-354.

Clark, G. 2005. "The Condition of the Working Class in England, 1209-2004." Working 
Paper \# 05 39. Davis.

Clark, G. 2008. "Welfare Reform, 1834." A paper presented at MIT Conference in Honor of Peter Temin.

Crafts, N.F.R. 1977. "Industrial Revolution in England and France: Some Thoughts on the Question, 'Why was England First?'" Economic History Review, 30(3): 429-41.

Crafts, N. F. 1985. English Workers' Real Wages During the Industrial Revolution:Some Remaining Problems. Journal of Economic History 45, Pp. 139-44.

de Vries, J. and A. van der Woude. 1997. The First Modern Economy: Success, Failure, and Perseverance of the Dutch Economy, 1500-1815. Cambridge: Cambridge University Press.

Deng, K. G. 2000. "A Critical Survey of Recent Research in Chinese Economic History." Economic History Review, LIII: 1-28.

Ebrey, P. B., A. Walthall, and J. B. Palais. 2005. East Asia: A Cultural, Social, and Political History. Boston: Houghton Mifflin Company.

Ebrey, P. B. and J. L. Watson. 1986. Kinship Organization in Late Imperial China 1000-1940. Berkeley: University of California Press.

Easterlin, R. A. 1981. "Why Isn't the Whole World Developed?" The Journal of Economic History, Vol. 41(1), pp. 1-19.

Einav, L. and Alma C. 2007. "Estimating Risk Preferences from Deductible Choice." American Economic Review, 97(3), June 2007, 745788.

Ekelund, R. B., Jr., R. F. Hébert, R. D. Tollison, G. M. Anderson, and A. B. Davidson. 1996. Sacred Trust: The Medieval Church as an Economic Firm. New York: Oxford University Press.

Fei, J. C. H. and Ts'ui-Jung Liu. 1982. "The Growth and Decline of Chinese Family Clans." Journal of Interdisciplinary History, Vol. 12, No. 3. (Winter), pp. 375-408.

Fenoaltea, S. 1976. "Risk, Transaction Costs, and the Organization of Medieval Agriculture." Explorations in Economic History. 13: 129-151.

Freedman, M. 1966. Chinese Lineage and Society: Fukien and Kwangtung. London: Athlone.

Freedman, M. 1958. Lineage Organization in Southeastern China. London: Athlone.

Galor, O. 2005. "The Transition from Stagnation to Growth: Unified Growth Theory." In: Durlauf, S., Aghion, P.(Eds.), Handbook of Economic Growth. North Holland, Amsterdam.

Galor, O. and D. Weil. 2000. "Population, Technology, and Growth: From Malthusian Stagnation to the Demographic Transition and Beyond." American Economic Review, September, 90(4), pp. 806-28.

Geremek, B. 1997. Poverty: A History. Translated by Agnreszka Kolakowska. Blackwell Publishing. 
Gollin, D., S. Parente and R. Rogerson. 2002. "The Role of Agriculture in Development," American Economic Review, 92(2), pages 160-164,

Goody, J. 1983. The Development of the Family and Marriage in Europe. Cambridge: Cambridge University Press.

Graham, J. R., Campbell R. Harvey, and Manju P. 2008. "Managerial Attitudes and Corporate Actions." Working Paper, Fuqua School of Business, Duke University.

Greif, A. 2006. Institutions and the Path to the Modern Economy. Cambridge: Cambridge University Press.

Greif, A. 1994. "Cultural Beliefs and the Organization of Society: Historical and Theoretical Reflection on Collectivist and Individualist Societies." Journal of Political Economy 102 (5): 91250.

Greif, A. 2005. "Commitment, Coercion, and Markets: The Nature and Dynamics of Institutions Supporting Exchange" In the Handbook for New Institutional Economics. Edited by C. Menard and MM. Shirley. Chapter 28.)

Grossman, H. I. (1994). "Production, Appropriation, and Land Reform," American Economic Review, 84(3), June, 705-12.

Grossman, H. I. and M. Iyigun. 1995. "The Profitability of Colonial Investment," Economics 83 Politics, 7:3, November, 229-24.

Grossman, H. I. and M. Kim. 1995. "Swords or Plowshares? A Theory of the Security of Claims to Property," Journal of Political Economy, 103(6), December, 1275-1288.

Guichard, P. and Cuvillier, J.-P. 1996. "Barbarian Europe." In Ed. André Burguiére et. al. A History of the Family, Vol. I. Cambridge: Polity Press. Pp. 318-378.

Guiso, L., P. Sapienza and L. Zingales. 2006. "Does Culture Affect Economic Outcomes?" Journal of Economic Perspectives 20: 23-48.

Halek, M. and J. G. Eisenhauer. 2001. "Demography of Risk Aversion." The Journal of Risk and Insurance, 68(1): 1 -24.

Hamilton, G. G. 1990. "Patriarchy, patrimonialism, and filial piety: A comparison of China and Western Europe." British Journal of Sociology, 41 (1): 77-104.

Hannon, J. 1984. "Poverty in the Antebellum Northeast: The View from New York State's Poor Relief Rolls." The Journal of Economic History, Vol. 44, No. 4., pp. 10071032 .

Hansen G.D. and E. Prescott. 2002. "Malthus to Solow." The American Economic Review, Vol. 92, No 4, pp. 1205-1217.

Harris, B. 2004. Public Health, Nutrition, and the Decline in Mortality: The McKeown Thesis Revisited. Social History of Medicine 17(3): 379-407.

Hausmann, R. and D. Rodrik. 2003. "Economic Development as Self-Discovery," Journal of Development Economics, vol. 72 (December): 606-36.

Hay, D. 1980. Crime and Justice in Eighteenth- and Nineteenth-Century England. Crime 
and Justice, Vol. 2, pp. 45-84.

Helpman, E. 2004. The Mystery of Economic Growth. Cambridge: Harvard University Press.

Herlihy, D. 1985. Medieval Households. Cambridge: Harvard University Press.

Hoff, K. and A. Sen. 2005. "The Kin System as a Poverty Trap?" World Bank Policy Research Working Paper 3575.

Homer, S. and R. Sylla. 1998. A History of Interest Rates. New Jersey: Wiley.

Hirshleifer, J. 1991. "The Paradox of Power," Economics \& Politics, 3:3, November, 177-200.

Iyigun, M. and D. Rodrik. 2005. "On the Efficacy of Reforms: Policy Tinkering, Institutional Change, and Entrepreneurship." In T. Eicher and C.G. Penalosa, eds., Institutions and Growth, Cambridge, MA: MIT Press.

Jones, I. C. 2001. "Was an Industrial Revolution Inevitable? Economic Growth over the Very Long Run." Advances in Macroeconomics, v1(2,Jun), 1-45.

Jütte, Robert. 1996. "Poverty and Poor Relief." In Sheilagh Ogilvie (ed.). Germany. A New Social and Economic History, 1630-1880. Vol. II. London: Arnold.

Kelly, M. and C. Ógrada. 2008. "The Poor Law versus Positive Check: Living standards and Mortality in England since the Middle Ages." UC Dublin working paper.

Khan, Z. B. 2008. "The Evolution of Useful Knowledge: Great Inventors, Science and Technology in British Economic Development, 1750-1930." Memo. Bowdoin College.

Khan, Z. B. 2005. "The Democratization of Invention: Patents and Copyrights in American Economic Development, 1790-1920." New York: Cambridge University Press.

Kocherlakota, R. Narayana. 1996. Implications of Efficient Risk Sharing without Commitment. Review of Economic Studies 63, 595-609.

Kremer, M. 1993. "Population growth and technological change: one million BC to 1990." Quarterly Journal of Economics, 108(3): 681-716.

Kremer, M. 1998. "Patent Buyouts: A Mechanism for Encouraging Innovation," Quarterly Journal of Economics, November, pp. 11371167.

Lal, D. 1998. Unintended Consequences: The Impact of Endowments, Culture, and Politics on Long-Run Economic Performance. Cambridge, MA: The MIT Press.

Landers J. 1987. Mortality and Metropolis: the case of London 1675-1825. Population Studies, 41:59-76.

Laslett, P. 1969." Size and Structure of the Household in England over Three Centuries." Population Studies, 23(2): 199-223.

Lawson, P. 1986. "Property Crime and Hard Times in England, 1559-1624." Law and History Review, 4: 95-127.

Lee, J. and W. Feng. 1999. Malthusian Models and Chinese Reality. The Chinese 
Demographic System 1700-2000. Population and Development Review 25(1), pp. 33-65.

Li, L. M. 1982. "Introduction: Food, Famine, and the Chinese State." The Journal of Asian Studies, Vol. 41(4) pp. 687-707.

Ligon, E., J. T. and T. Worrall. 2000. "Mutual Insurance, Individual Savings and Limited Commitment," Review of Economic Dynamics, Academic Press for the Society for Economic Dynamics, vol. 3(2), pages 216-246.

Lindert, P. H. 2004. Growing Public. Cambridge: Cambridge University Press.

Liu C. [Liu Ts'ui-Jung]. 1992. Ming Qing shiqi jiazu renkou yu shehui jingji bianqian (Lineage populations and socio-economic change in the Ming-Qing period), vol. 2. Taibei: Zhongyang yanjiuyuan jingji yanjiusuo.

Liu, H.-C. Wang. 1959. The Traditional Chinese lineage Rules. Now York: Augustin Inc. Publisher.

Lucas Jr., R. 2002. Lectures on Economic Growth. Harvard University Press.

Maddison, A. 1991. Dynamic Forces in Capitalist Development: A Long-Run Comparative View. Oxford: Oxford University Press.

Mitterauer, M. and R. Sieder. 1982. The European Family. Oxford: Basil Blackwell.

Mokyr, J. 1990. The lever of riches: Technological creativity and economic progress. Oxford: Oxford University Press.

Mokyr, J. 1999. Editor's Introduction: The New Economic History and the Industrial Revolution. In Joel Mokyr, ed., The British Industrial Revolution: an Economic Perspective. Boulder: Westview Press, 2nd ed., 1999, pp. 1-127.

Mokyr, J. 2002. "Why was the Industrial Revolution a European Phenomenon?", Supreme Court Economic Review 9.

Mokyr, J. 2005. "Long-term Economic Growth and the History of Technology." In the Handbook of Economic Growth, Volume 1B. Edited by Philippe Aghion and Steven N. Durlauf. Elsevier B.V., pp. 1114-1180.

Mokyr, J. 2006. "Entrepreneurship and the Industrial Revolution in Britain." Memo. Northwestern University

Mokyr, J. 2007. The European Enlightenment, the Industrial Revolution, and Modern Economic Growth. The Max Weber Lecture Series. 2007/6.

Mokyr, J. 2010. The Enlightened Economy: An Economic History of Britain 1700-1850, (New Haven, CT: Yale University Press).

Nef, U. J. 1940. Industry and Government in France and England 1540-1640. Ithaca and London: Cornell University Press.

Nicolini, E. A. 2007. Was Malthus Right? A VAR Analysis of Economic and Demographic Interactions in Pre-industrial England. European Review of Economic History, $11,99-121$. 
North, D. C. 1990. Institutions, Institutional Change and Economic Performance. Cambridge: Cambridge University Press.

North, D. C. 2005. Understanding the Process of Institutional Change. Princeton University Press.

North, D. C., and B. R. Weingast. 1989. "Constitutions and Commitment: The Evolution of Institutions Governing Public Choice in Seventeenth-Century England." The Journal of Economic History 49: 803-32.

Outhwaite, R. B. 1991. Dearth, Public Policy and Social Disturbance in England 15501800 (New Studies in Economic and Social History). Cambridge University Press.

Patriquin, L. 2006. "Why was there no 'Old Poor Law' in Scotland and Ireland?" Journal of Peasant Studies, 33(2) pp. 219-247.

Pomeranz, K. 2000. The Great Divergence: China, Europe and the Making of the Modern World Economy. Princeton, NJ: Princeton University Press.

Razi Z. 1993. "The Myth of the Immutable English Family." Past \& Present 140(Aug), Pp. 3-44.

Razzell, P. 1994. Essays in English Population History. Hampstead.

Riley, W. B. Jr. and K. V. Chow. 1992. "Asset Allocation and Individual Risk Aversion." Financial Analysts Journal, Vol. 48 (Dec. 6): 3237.

Reynolds, S. 1984. Kingdoms and Communities in Western Europe, 900-1300. Oxfrod: Clarendon Press.

Richardson, G. 2005. "The Prudent Village: Risk Pooling Institutions in Medieval English Agriculture." Journal of Economic History, 65(2) (June): 386-413.

Rodrik, D., A. Subramanian and F. Trebbi. 2004. "Institutions Rule: the Primacy of Institutions over Geography and Integration in Economic Development." Journal of Economic Growth, 2004, v9(2,Jun), 131-165.

Romer, P. M. 1986. "Increasing Returns and Long-run Growth," Journal of Political Economy, 94(5), pages 1002-37.

Rowe, W. T. 1998. "Ancestral Rites and Political Authority in Late Imperial China Chen Hongmou in Jiangxi." Modern China, vol. 24(4): 378 -407.

Schofield, P. R. 2003. Peasants and Community in Medieval England, 1200-1500. New York: Palgrave.

Shiue, C. H. and W. Keller. 2007. "Markets in China and Europe on the Eve of the Industrial Revolution." American Economic Review, 97(4), pp. 1189-1216.

Slack, P. 1990. The English Poor Law, 1531-1782. London: Macmillan.

Smith, J. F. H. 1987. "Benevolent Societies: The Reshaping of Charity during the Late Ming and Early Ch'ing." The Journal of Asian Studies, 46(2): 309- 37.

Smith, R. 2008. "Social Security as a Developmental Institution? Extending the Solar 
Case for the Relative Efficacy of Poor Relief Provisions under the English Old Poor Law." Brooks World Poverty Institute Working Paper No. 56

Solar, P. M. 1995. "Poor Relief and English Economic Development before the Industrial Revolution." The Economic History Review, New Series, Vol. 48 (1), pp. 1-22.

Steckel, R. and Floud, R. (Eds.) (1997). Health and Welfare During Industrialization. Chicago: University of Chicago Press.

Sullivan, R. J., 1984. "Measurement of English Farming Technological Change, 15231900." Explorations in Economic History, Vol. 21, pp. 270-289.

Sullivan, R. J. 1989. "England's Age of Invention: the Acceleration of Patents and Patentable Invention During the Industrial Revolution." Explorations in Economic History, Vol. 26(4), pp. 424-452.

Szonyi, M. 2002. Practicing Kinship. Lineage and Descent in Late Imperial China. Stanford. Stanford University Press.

Tabellini, G. 2005. "Culture and Institutions: Economic Development in the Regions of Europe," IGIER discussion paper.

Tauchen, G. and R. Hussey. 1991. Quadrature-Based Methods for Obtaining Approximate Solutions to Linear Asset Pricing Models. Econometrica, 59(2), 371-396.

Tauchen, G. 1986. Finite State Markov-Chain Approximation to Univariate and Vector Autoregression. Economics Letters, 20, 177-181.

Van Praag, C. M. And J. S. Cramer. 2001. "The Roots of Entrepreneurship and Labour Demand: Individual Ability and Low Risk Aversion." Economica, New Series, 68(no. 269, Feb): 4562.

Voigtländer, N. and H.-J. Voth. 2006. "Why England? Demographic Factors, Structural Change and Physical Capital Accumulation during the Industrial Revolution." Memo. Universitat Pompeu Fabra.

Watson, J. L. 1982. "Chinese Kinship Reconsidered: Anthropological Perspectives on Historical Research." The China Quarterly, No. 92. (Dec., 1982), pp. 589-622.

Weir, D. R. 1997. Economic Welfare and Physical Well-being in France, 1750-1990. In R. H. Steckel and R. Floud (Eds.), Health and Welfare During Industrialization, Vol. I, Pp. 161-200. Chicago: University of Chicago Press.

Wiens, T. B. 1976. "Peasant Risk Aversion and Allocative Behavior: A Quadratic Programming Experiment." American Journal of Agricultural Economics, (58, No. 4, Nov.): 62935 .

Wong Bin, R. 1982. "Food Riots in the Qing Dynasty." The Journal of Asian Studies, Vol. 4(4) pp. 767-788.

Zak, P. J., and S. Knack. 2001. "Trust and Growth." Economic Journal 111 (470): 295-321. 
Table 1: Parameter Choices

Panel A: Demographics and Preferences

\begin{tabular}{|lccccc|}
\hline & \multicolumn{5}{l}{} \\
\hline Description & (Annual) & (Model) & (Per.Period) \\
& Value & Parameter & Value & Method \\
\hline 20 year periods & - & - & - & - \\
Number of newly born in each generation & - & $\mathrm{N}$ & 144 & $\mathrm{H}$ \\
Survival probability & 0.966 & $\lambda$ & 0.5 & $\mathrm{H}$ \\
Discount factor & 0.975 & $\beta$ & 0.603 & $\mathrm{M}$ \\
Risk aversion coefficient & 5 & $\omega$ & - & $\mathrm{M}$ \\
Subsistence level of consumption for young & 0 & $\mathrm{C}^{\mathrm{y}}$ & - & $\mathrm{C}$ \\
Subsistence level of consumption for elderly & 0.06 & $\mathrm{C}^{\circ}$ & - & $\mathrm{C}$ \\
\hline & & & & \\
\hline
\end{tabular}

Panel B: Technology Choices

\begin{tabular}{|lccccc|}
\hline & \multicolumn{7}{c|}{} \\
\hline Description & (Annual) & (Model) & (Per-Period) & \\
\hline Avg. growth rate for LR technology & 0 & $\mu_{\mathrm{LR}}$ & 0 & $\mathrm{H}$ \\
Avg. growth rate for HR technology & 0.005 & $\mu_{\mathrm{HR}}$ & 0.113 & $\mathrm{H}$ \\
Stand. dev. of innovations for LR technology & $? ? ?$ & $\sigma_{\mathrm{LR}}$ & 0.015 & $\mathrm{C}$ \\
Stand. dev. of innovations for HR technology & $? ? ?$ & $\sigma_{\mathrm{HR}}$ & 0.19 & $\mathrm{C}$ \\
Insurance effectiveness under the Poor Law & - & $\Psi_{\mathrm{PL}}$ & $1 / 17$ & $\mathrm{C}$ \\
\hline
\end{tabular}

Panel C: Residual Parameters

\begin{tabular}{|c|c|c|c|c|c|}
\hline \multicolumn{2}{|c|}{ Description } & $\begin{array}{l}\text { (Annual) } \\
\text { Value }\end{array}$ & $\begin{array}{c}\text { (Model) } \\
\text { Parameter }\end{array}$ & $\begin{array}{l}\text { (Per-Period) } \\
\text { Value }\end{array}$ & Method \\
\hline \multicolumn{2}{|c|}{ Share of land } & 0.33 & $\alpha$ & - & M \\
\hline \multicolumn{2}{|c|}{ Exogenous interest rate } & 0.045 & $\mathrm{r}$ & 1.412 & $\mathrm{H}$ \\
\hline \multicolumn{2}{|c|}{ Depreciation rate } & 0.03 & $\bar{\delta}$ & 0.543 & M \\
\hline Method: & $\begin{array}{l}\text { Historical Evidence }(\mathrm{H}) \\
\text { Modern Data }(\mathrm{M}) \\
\text { Calibration }(\mathrm{C})\end{array}$ & & & & \\
\hline
\end{tabular}


Table 1: Parameter Choices (continued)

Panel D: All Parameter Choices

\begin{tabular}{|c|c|c|}
\hline Parameter & Value & Description \\
\hline$\lambda$ & 0.5 & 20-year survival probability \\
\hline$\beta$ & 0.603 & (Annual) discount factor is 0.975 \\
\hline A & $0.8-6$ & state space for technology of production \\
\hline B & $0.1-6$ & state space for technology of appropriation \\
\hline k & $0.1-3$ & state space for capital stock \\
\hline$\omega$ & 5 & Risk aversion coefficient at high levels of wealth \\
\hline cy & 0 & Subsistence level of consumption for young \\
\hline co & 0.06 & Subsistence level of consumption for elderly \\
\hline$\mu \mathrm{LR}$ & 0 & Average annual growth rate for low risk / low reward technology is zero \\
\hline$\mu \mathrm{HR}$ & 0.113 & Average annual growth rate for high risk / high reward technology is $0.5 \%$ \\
\hline$\sigma \mathrm{LR}$ & 0.015 & Standard deviation of innovations under low risk / low reward technology \\
\hline$\sigma \mathrm{HR}$ & 0.19 & Standard deviation of innovations under high risk / high reward technology \\
\hline$\sigma 1$ & 1 & standard deviation of high income inequality under low risk / low reward technology \\
\hline$\sigma 2$ & 3.25 & standard deviation of high income inequality under high risk / high reward technology \\
\hline$\sigma 3$ & 0.3 & standard deviation of low income inequality under low risk / low reward technology \\
\hline$\sigma 4$ & 1 & standard deviation of low income inequality under high risk / high reward technology \\
\hline a & 0.33 & Share of land \\
\hline r & 1.412 & (Annual) interest rate is $4.5 \%$ \\
\hline $\bar{\delta}$ & 0.543 & (Annual) depreciation rate is $3 \%$ \\
\hline $\mathrm{N}$ & 144 & Number of newly born agents in each generation \\
\hline$\psi \mathrm{PL}$ & $1 / 17$ & Insurance effectiveness under the Poor Law \\
\hline
\end{tabular}


Figure 1:

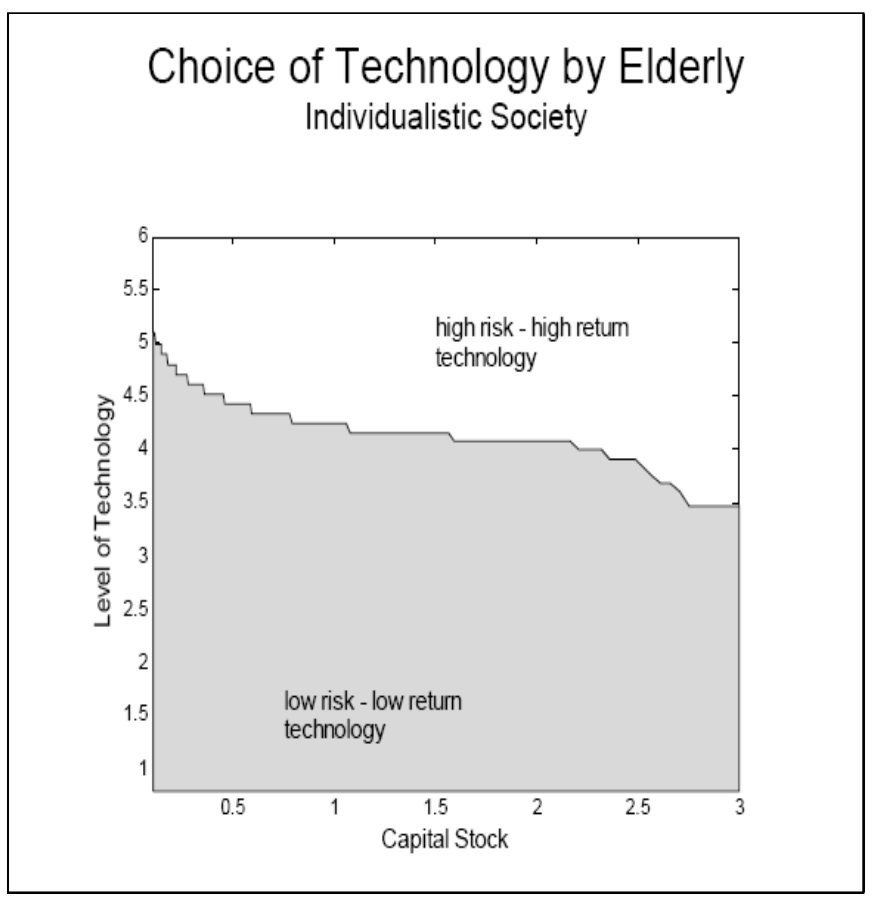

Figure 2:

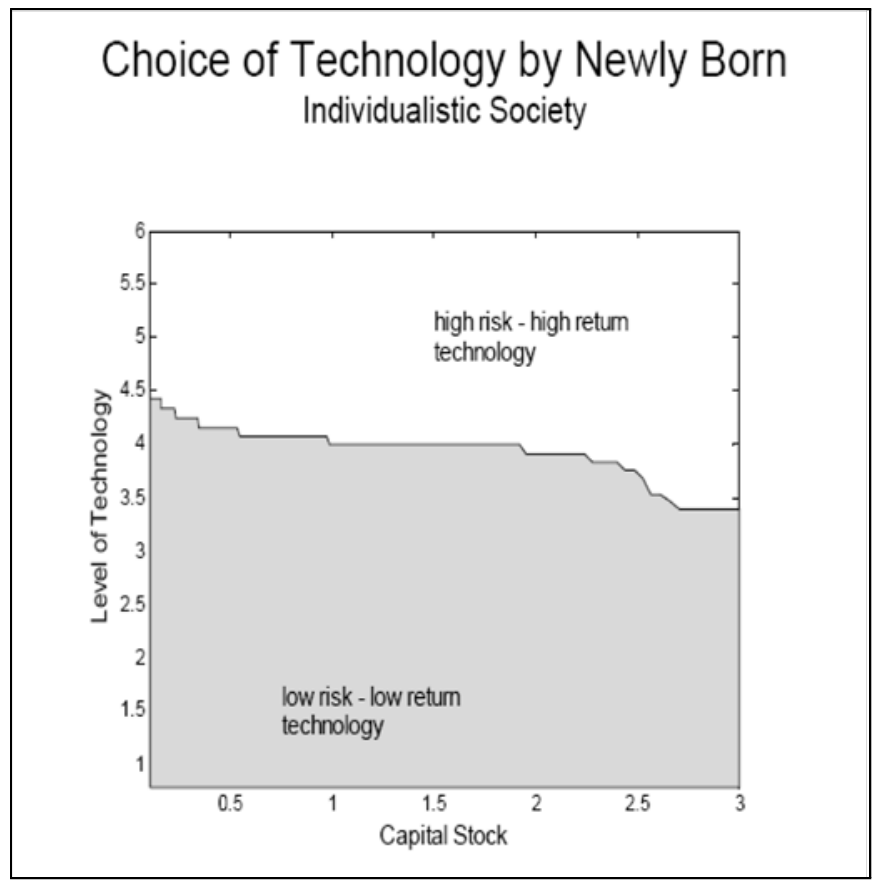


Figure 3:

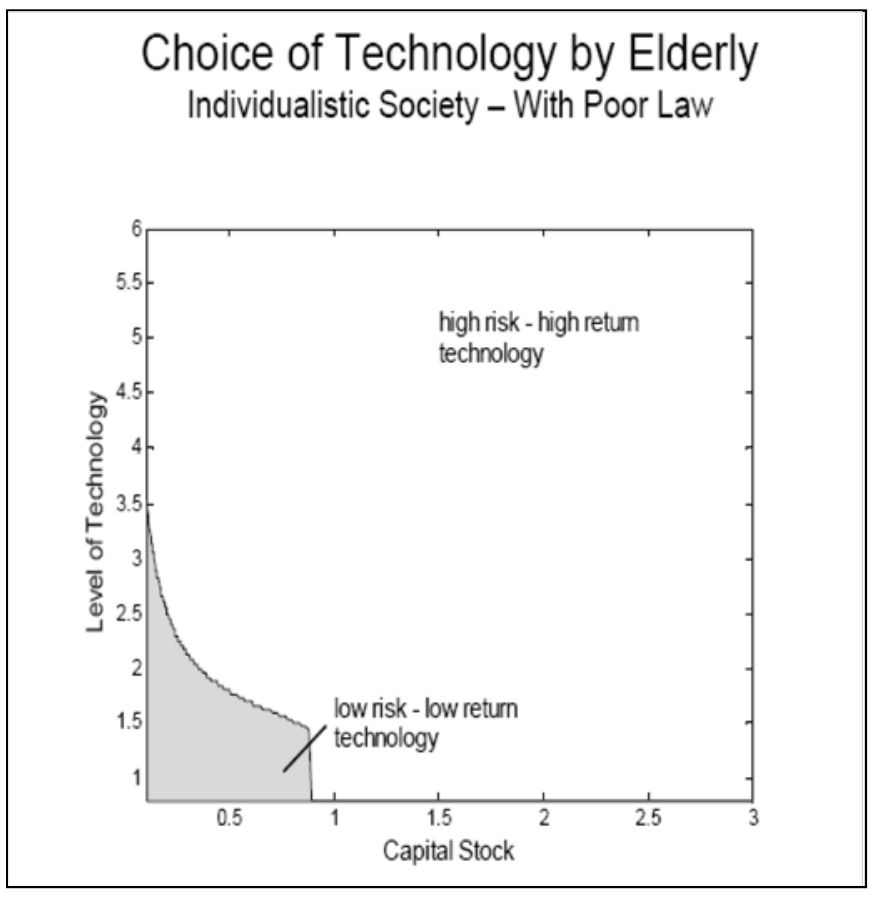

Figure 4:

Choice of Technology by Newly Born Individualistic Society - With Poor Law

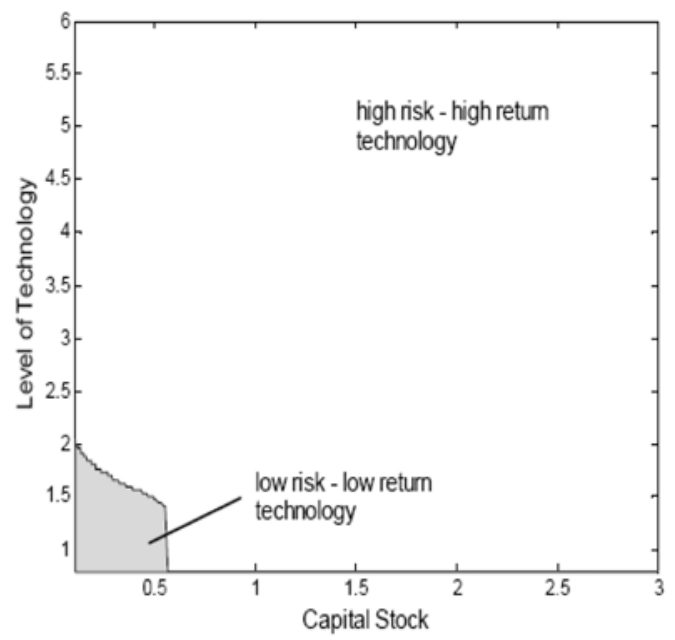


Figure 5:

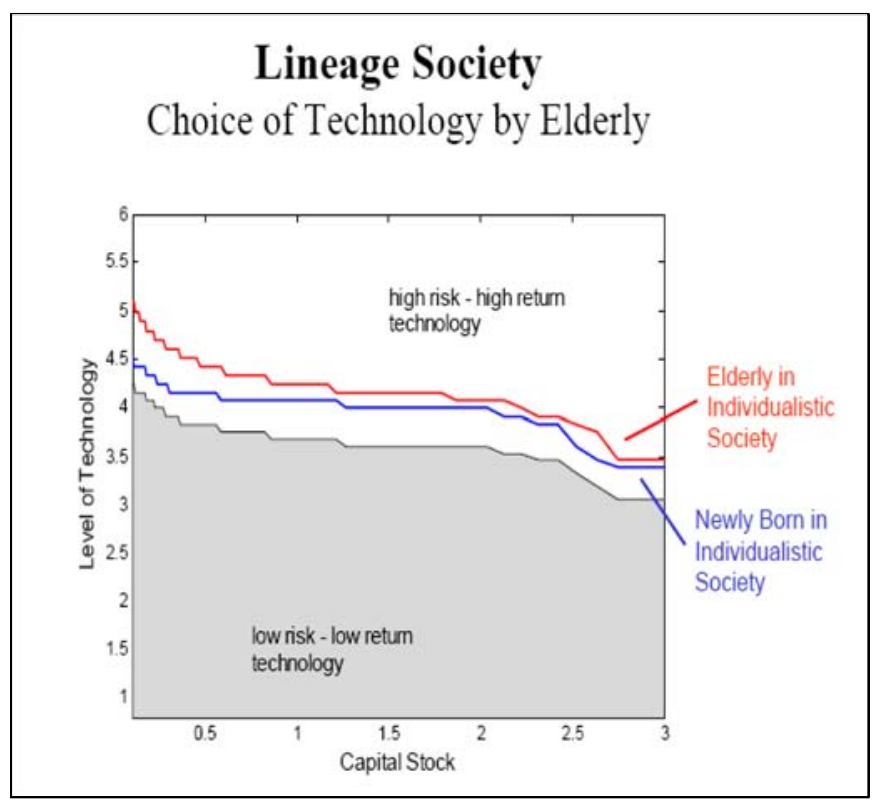

Figure 6:

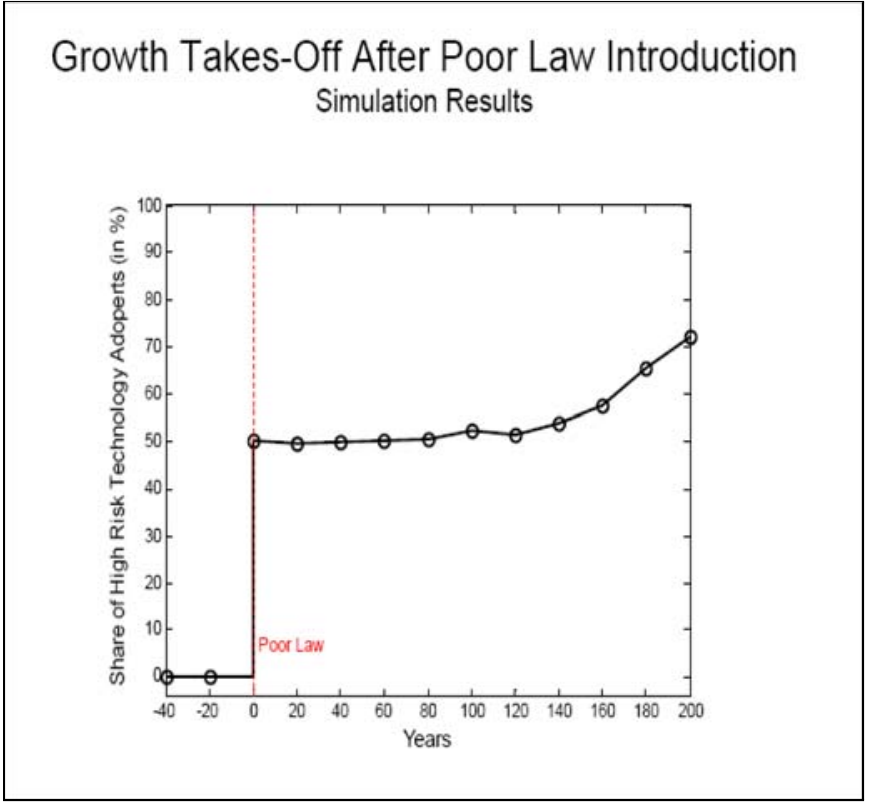


Figure 7:

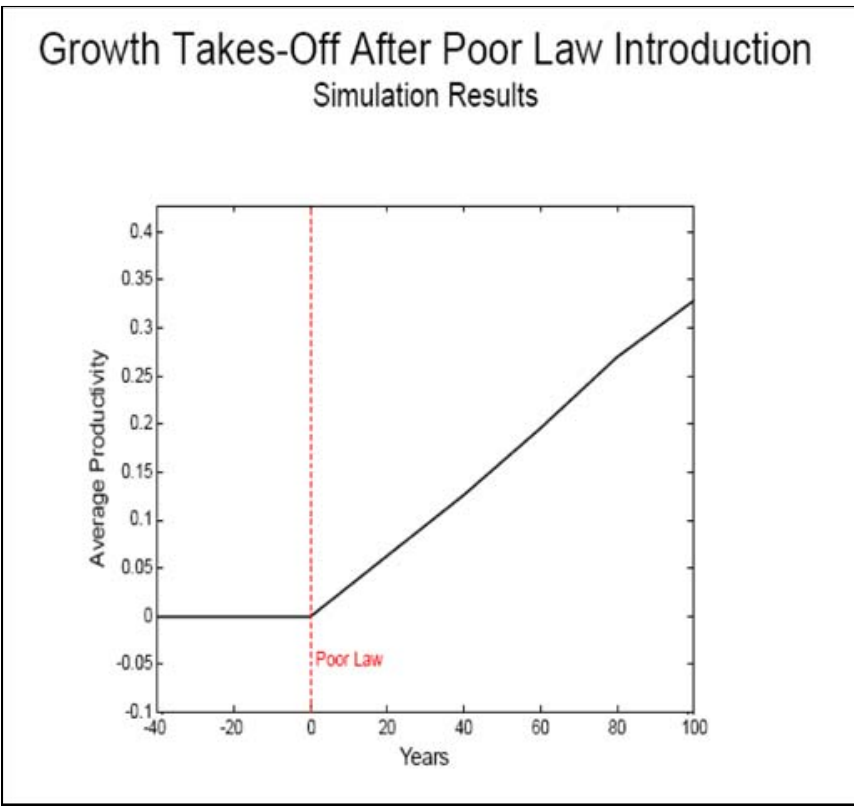

Figure 8:

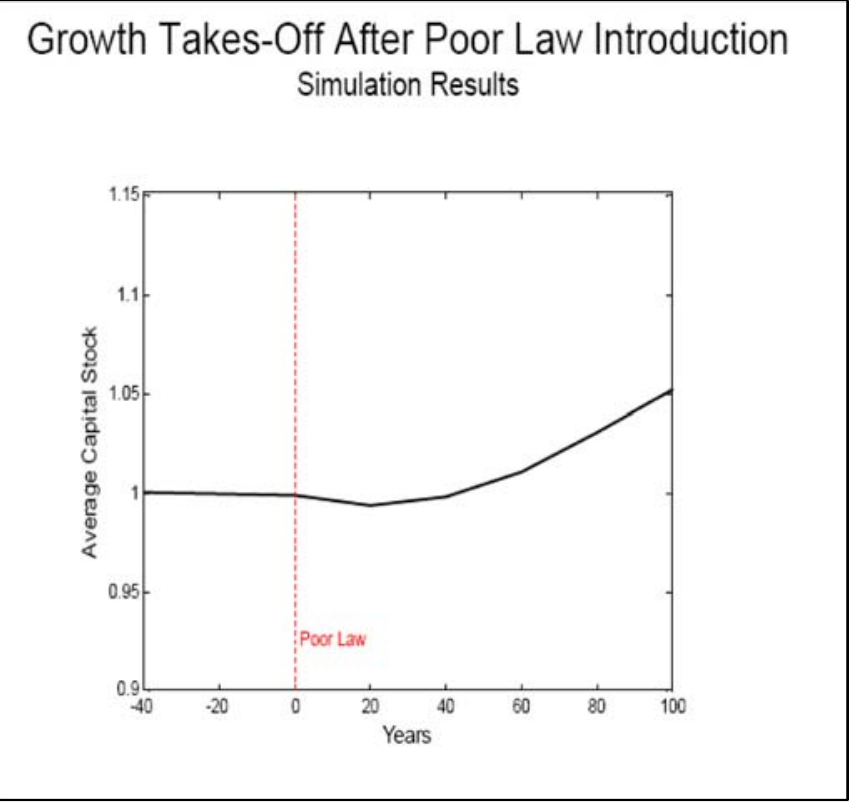


Figure 9:

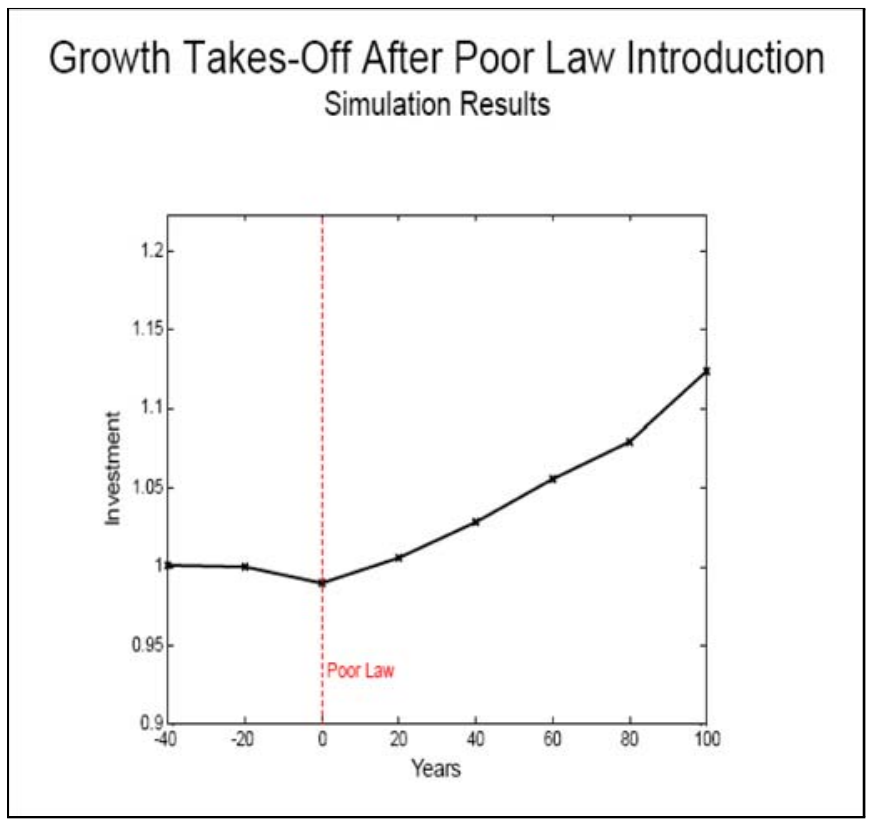

Figure 10:

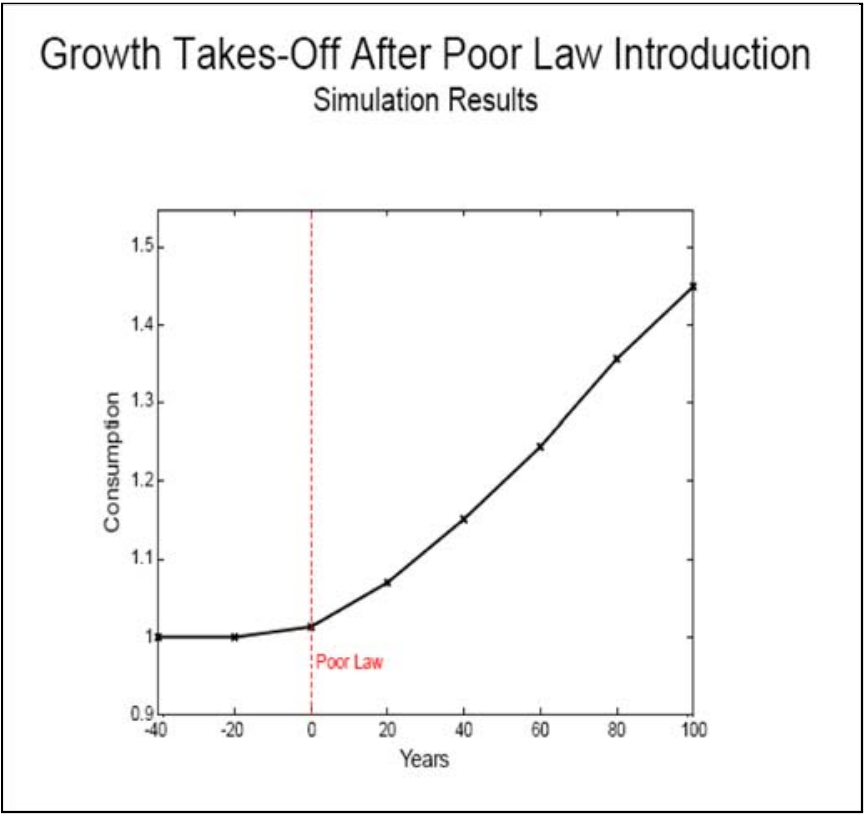


Figure 11:

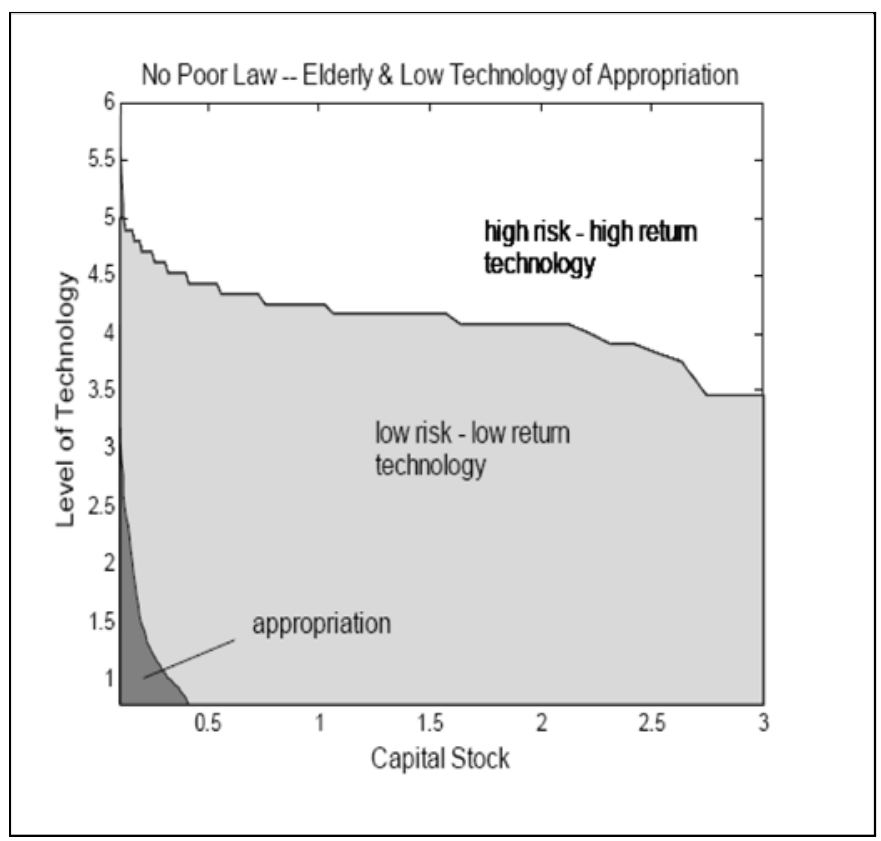

Figure 12:

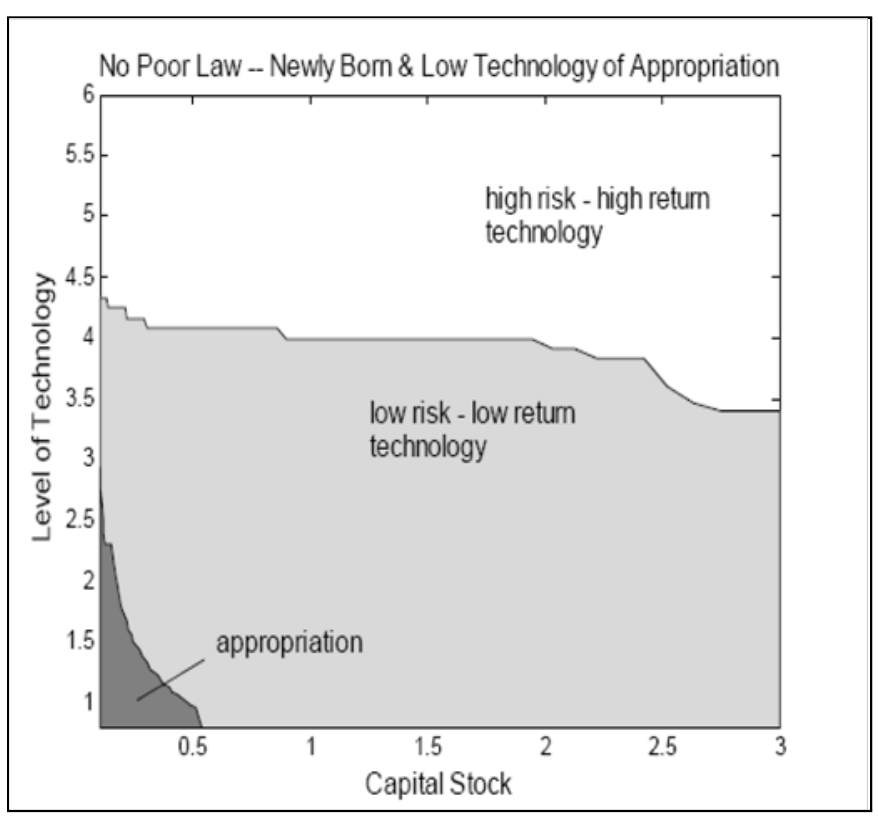




\section{Figure 13:}

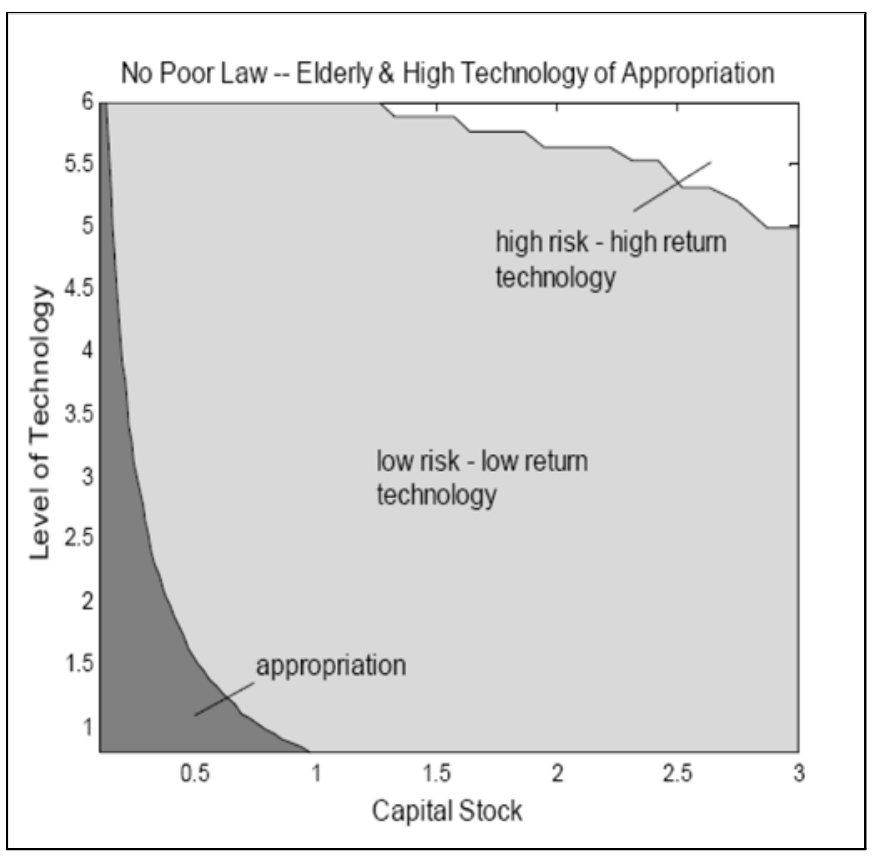

Figure 14:

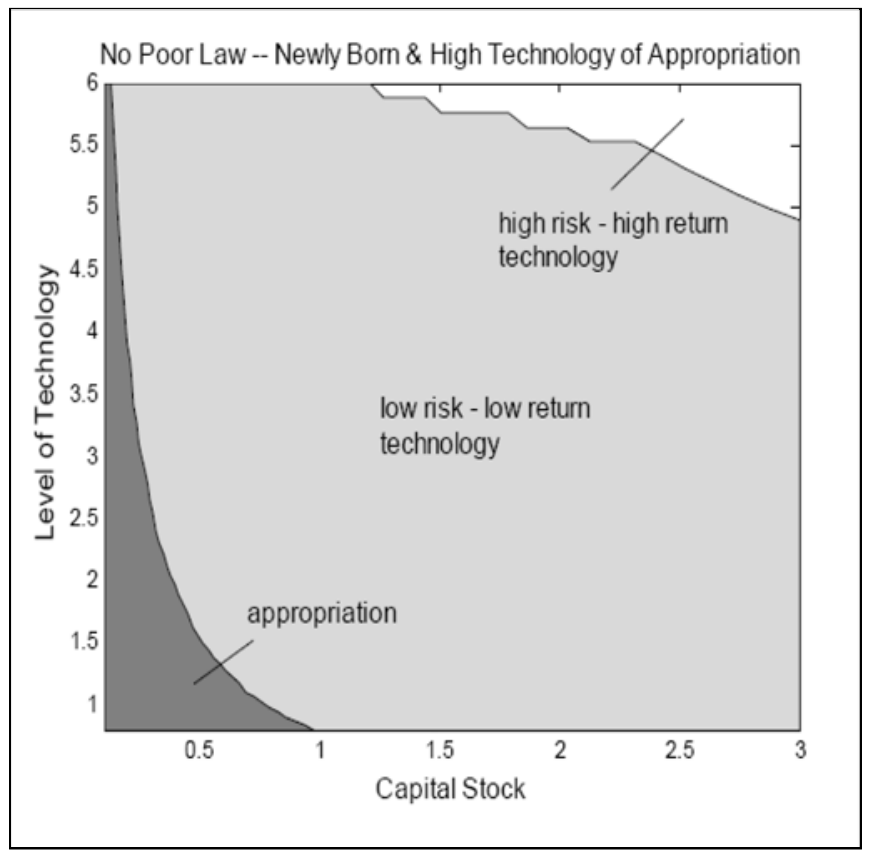


Figure 15:

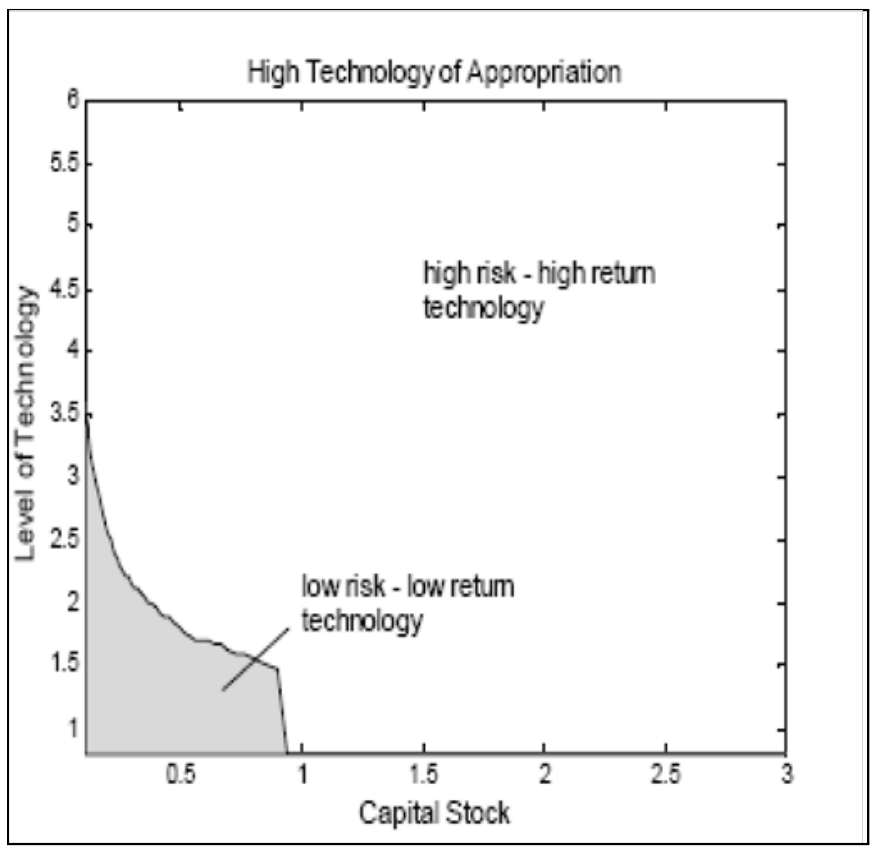

Figure 16:

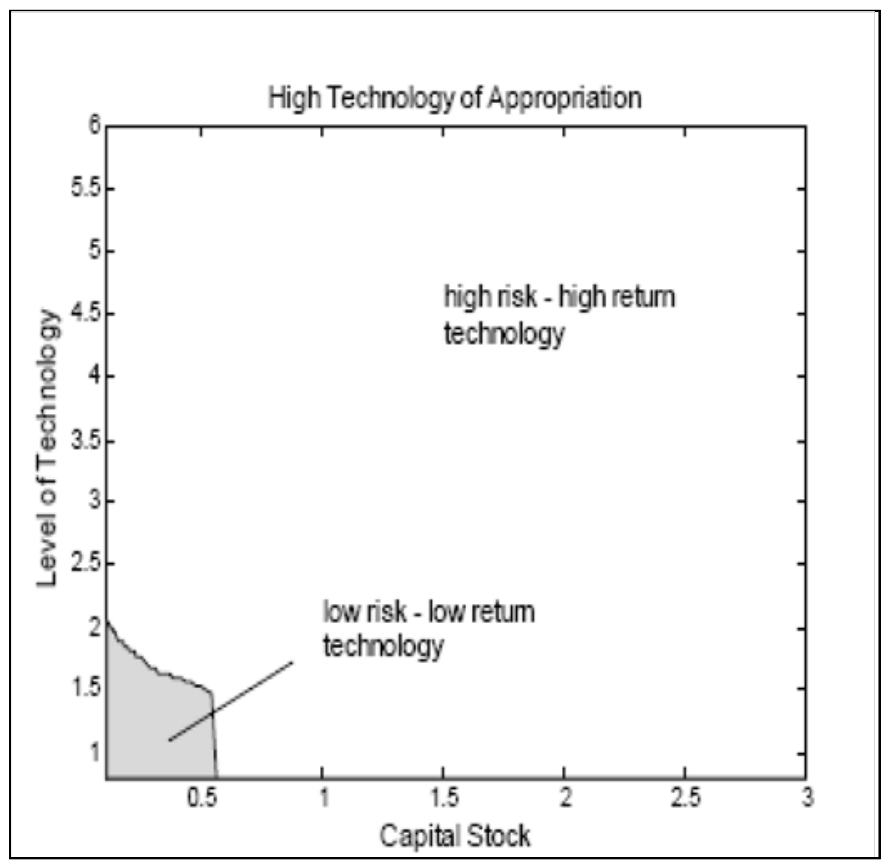


Figure 17:

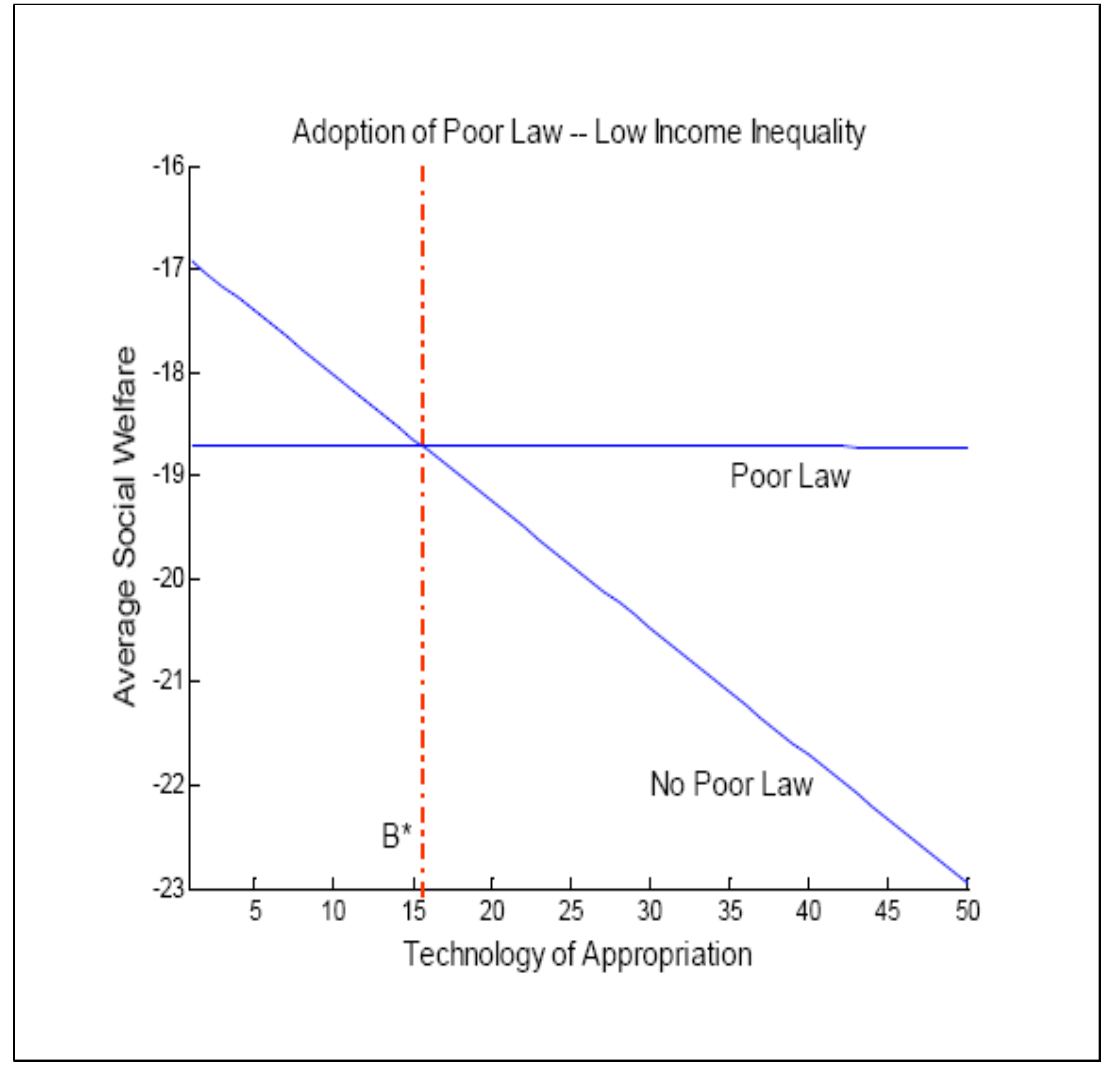




\section{Appendix A: The Productivity Level and Optimal Technol- ogy}

Remark 1 For every state of the world and social arrangement $(r=m, P L$, or $\Gamma)$ there is a pair of productivity levels $\left\{\underline{A_{y}^{r}}, \underline{A_{o}^{r}}\right\}$ such that if $A_{t}<\underline{A_{y}^{r}}$, LR technology is optimal for all agents; if $A_{t} \in\left[\underline{A_{y}^{r}}, \underline{A_{o}^{r}}\right]$, the $H R(L R)$ is optimal for the newly born (young adult and older agents); and if $A_{t}>\underline{A_{o}^{r}}$, HR technology is optimal for all agents.

Proof. The preferences depend on the comparison between the two technological regimes, that can be viewed as two lotteries. The decision of the newly-born agents depends on:

$$
\begin{gathered}
\operatorname{sign} E_{A_{t+1} \mid A_{t}} V_{2}^{r}\left(A_{t+1}, k_{t+1} \mid\left(A_{t}, k_{t}\right), H R\right)-E_{A_{t+1} \mid A_{t}} V_{2}^{r}\left(A_{t+1}, k_{t+1} \mid\left(A_{t}, k_{t}\right), L R\right) \\
\text { for } r=m, P L, \text { or } \Gamma
\end{gathered}
$$

The young adult and the older agents always have the same optimal technology. The choice of technology impacts on next period utility, where both types of agents will have the same (elderly type) preferences. Their decision depends on:

$$
\begin{gathered}
\operatorname{sign} E_{A_{t+1} \mid A_{t}} V_{3}^{r}\left(A_{t+1}, k_{t+1} \mid\left(A_{t}, k_{t}\right), H R\right)-E_{A_{t+1} \mid A_{t}} V_{3}^{r}\left(A_{t+1}, k_{t+1} \mid\left(A_{t}, k_{t}\right), L R\right) \\
\text { for } r=m, P L \text { or } \Gamma
\end{gathered}
$$

Since all the agents have DRRA utility functions, given the state variables $\left(A_{t}, k_{t}\right)$, there is a threshold productivity value, $\left\{\underline{A_{y}^{r}}, \underline{A_{o}^{r}}\right\}$, such that for any value below that threshold agents choose the low-risk regime and for any value above that threshold they choose the high-risk regime in each of the social structure organizations. Since elderly agents are more risk averse than young agents $\underline{A_{y}^{r}}<\underline{A_{o}^{r}}$. This determines three zones. Given $\left(A_{t}, k_{t}\right)$, if $A_{t}<A_{y}^{r}$, there is unanimity and all the agents favor the low risk-low return regime. If $A_{t} \in\left[\underline{A_{y}^{r}}, \underline{A_{o}^{r}}\right]$ newly born favor the high-return regime while the rest of the agents the low-return regime. If $A_{t}>A_{o}^{r}$, all the preferences are realigned again and everybody favors the high-return regime.

\section{Appendix B: Appropriation Risk and Social Risk-Sharing}

Suppose that all individuals can allocate their efficiency units of capital to either extralegal appropriation or production. Further, assume that only a fraction $\rho$ of the population can organize to engage in extralegal appropriation which also requires the use of capital. ${ }^{56}$

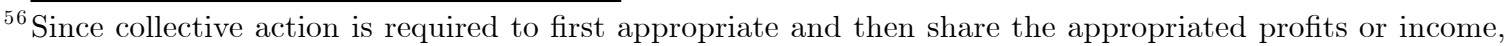
there are inherent free-rider problems associated with extralegal appropration (see, for example, Grossman,
} 
Individuals who partake in extralegal appropriation target the rest of the population, $1-\rho$, and appropriation only covers the contemporaneous return to capital or profits. In other words, we assume that capital ownership is secure and cannot be appropriated, while the income streams generated from capital are up for grabs in every period.

In every period $t$, individuals decide whether or not to engage in production versus appropriation. And in doing so, they consider their return from extralegal appropriation net of its opportunity cost. For each individual $i$, the latter is defined by their forgone earnings from production at time $t$. For newly-born individuals, $i=1$, this equals their profits from production, given by $\pi_{t}\left(A_{t}^{i}, k_{t}^{i}, r\right)=(1-\alpha)\left(\frac{\alpha}{r}\right)^{\frac{\alpha}{1-\alpha}}+r A_{t}^{i} k_{t}^{i}$. For young adults and older generations, $i=2,3$, the opportunity cost is their net return from rental capital, which equals $r A_{t}^{i} k_{t}^{i}-\left(k_{t+1}^{i}-(1-\delta) k_{t}^{i}\right)$. Thus, the opportunity cost of extralegal means would be lowest for those who possess low incomes - either because their stock of capital is low, or their adopted technology is inferior, or both. Accordingly, ceteris paribus, the poorest $\rho$ fraction of society would engage in extralegal means.

Following standard convention, we employ a contest success function in order to determine the gross return from extralegal activities. Hence, letting $B$ represent the technology of appropriation and $b_{t}=\sum_{i=1}^{\frac{\rho}{1-\lambda}} k_{t}^{i}$ denote the total amount of resources $\rho$ fraction of individuals devote to appropriation, we have

$$
\Gamma_{t}=\frac{B b_{t}}{1+B b_{t}}
$$

Equation (B.1) can be interpreted in one of two ways: either, it represents the fraction of the targeted income that are eventually appropriated by those who engage in extralegal appropriation, or it is the probability that the targeted income is fully captured by those who pursue extralegal appropriation. According to the former interpretation, those who engage in production lose $\Gamma_{t}$ fraction of their income to extralegal activities and salvage $1-\Gamma_{t}$ fraction of their income. With the second interpretation, those who are specialized in production avoid losing any of their income with $1-\Gamma_{t}$ probability. In either case, the success of appropriative activities is increasing in the total amount of resources devoted to it, $b_{t}$, and in the technology of appropriation, $B$. In deciding their mode of economic action, note that each individual $i$ takes $b_{t}$ as given, which in turn makes $\Gamma_{t}$ given.

Due to (B.1), it is clear that those who engage in appropriation would target the wealthiest members of the economy. ${ }^{57}$ Hence, letting $G_{t}$ denote the cumulative distribution function of the efficiency units of capital in the economy at time $t$, we have

1994). We think of the fraction $\rho$ as constituting a small enough group that could overcome such free-riding. ${ }^{57}$ The contest success function we employ here is most parsimonious in that it excludes reasonable other factors, such as resources that the 'target' could devote to defend their property or wealth and the technology of defense. With more complicated but realistic contest success functions, it is possible that, under some parameter values, the wealthiest individuals wouldn't be targeted by those who choose to devote their resources and time to extralegal means. 


$$
\int_{\widetilde{A_{t} k_{t}}}^{\infty} G_{t}^{\prime}(x) d x=1-\rho
$$

as the fraction of society targeted by extralegal appropriation, and

$$
\int_{0}^{\widetilde{A_{t} k_{t}}} G_{t}^{\prime}(x) d x=\rho
$$

which defines the fraction of population at the bottom end of the wealth distribution who specialize in extralegal appropriation instead of production. In (B.2.a) and (B.2.b), $\widetilde{A_{t} k_{t}}$ is jointly defined by $G_{t}($.$) and \rho$ so that, if all individuals with efficiency capital endowments of $\widetilde{A_{t} k_{t}}$ and more are targeted, then $1-\rho$ fraction of the economy is subject to appropriation risk.

Using (B.1), (B.2.a) and (B.2.b), and assuming that the captured profits are shared equally among those who pursue extralegal means, the net return to extralegal appropriation at time $t$ equals, $\forall i=1$,

$\frac{(1-\lambda) \Gamma_{t}}{\rho}\left[r \int_{\frac{A_{t} k_{t}}{\infty}}^{\infty} x G_{t}^{\prime}(x) d x+\frac{\lambda}{(1-\lambda)}(1-\alpha)\left(\frac{\alpha}{r}\right)^{\frac{\alpha}{1-\alpha}} \int_{\frac{A_{t} k_{t}}{\infty}}^{\infty} G_{t}^{\prime}(x) d x\right]-\left[(1-\alpha)\left(\frac{\alpha}{r}\right)^{\frac{\alpha}{1-\alpha}}+r A_{t}^{i} k_{t}^{i}\right]$,

and, $\forall i=2,3$,

$\frac{(1-\lambda) \Gamma_{t}}{\rho}\left[r \int_{\frac{A_{t} k_{t}}{\infty}}^{\infty} x G_{t}^{\prime}(x) d x+\frac{\lambda}{(1-\lambda)}(1-\alpha)\left(\frac{\alpha}{r}\right)^{\frac{\alpha}{1-\alpha}} \int_{\frac{A_{t} k_{t}}{\infty}}^{\infty} G_{t}^{\prime}(x) d x\right]-\left[r A_{t}^{i} k_{t}^{i}-\left(k_{t+1}^{i}-(1-\delta) k_{t}^{i}\right)\right]$.

With these modifications at hand, individuals' dynamic problem presented in equations (4.a) through (4.c) would, in every period $t$, involve a third decision (in addition to those of technology and saving): to choose between production and appropriation.

Ceteris paribus, equations (B.3.a) and (B.3.b) are more likely to be positive for the bottom $\rho$ fraction of individuals in more unequal economies (those with higher $\sigma_{j}^{2}$ 's) and with sufficiently effective technologies of appropriation (i.e., those with high $B$ 's). In 
economies with inherently higher income risk, inequality is higher. In such economies, not only the income of the target population, $\int_{\widetilde{A_{t} k_{t}}}^{\infty} x G_{t}^{\prime}(x) d x$, is relatively larger, but also the opportunity cost of appropriation - the terms in square brackets in (B.3.a) and (B.3.b) - is relatively lower for more people at the lower end of the capital distribution. And when (B.3.a) and (B.3.b) are satisfied for the poorest $\rho$ fraction of a population, only $1-\rho$ fraction of the economy is engaged in productive activities and all of the latter are subject to appropriative risk.

There are three possible equilibrium outcomes in such economies. First, there is an appropriation equilibrium which we just described, with the poorest $\rho$ fraction of the economy pursuing extralegal, appropriative means and the $1-\rho$ fraction engaged in production. In such an equilibrium, there is always some appropriation and all producers face a positive risk of appropriation every period.

In addition, there are two other equilibria, both of which require some coordination among the rich: In the risk-sharing equilibrium, the producers (or the rich) coordinate to tax themselves and use the proceeds for transfers to the poorest $\rho$ fraction of the society. In such an equilibrium, the per-person amount of transfers to the poor are such that (B.3.a) and (B.3.b) are non-positive for all of the poorest $\rho$ fraction of individuals. Accordingly, there is no appropriation here with the rich choosing to experiment with high-risk technologies. ${ }^{58}$

But, in an attempt to limit appropriation risk, the rich could also coordinate among themselves to suppress experimentation with high-risk technologies. In this case, which we label as the appropriation-cum-stagnation equilibrium, there is no tax-and-transfer scheme. Instead, income growth and risk among the rich as well as wealth inequality in society is limited because coordination among the rich ensures that they all employ the low-risk and low-return technology. This, in turn, lowers the gross return from extralegal appropriation - given by the first terms of the equations in (B.3.a) and (B.3.b) - and serves to reduce appropriation incentives among the poor. ${ }^{59}$

Together with the capital distribution and the technology of appropriation given in (B.1), the costs of coordination would determine which of the three equilibria would hold.

\footnotetext{
${ }^{58}$ According to (B.3.a) and (B.3.b), the transfer amount that would dissuade each individual from choosing appropriation is individual specific, depending on the wealth of each individual. Thus, if transfers cannot be individual specific, then an identical amount of transfer to all poor individuals would suffice to eliminate appropriation risk, as long as the transfer amount is determined by (B.3.a) and (B.3.b) evaluated for the wealthiest among the $\rho$ fraction of the economy.

${ }^{59}$ One other possibility is that the rich coordinate to fend off extralegal appropriation by investing in defensive activities. The simple appropriation technology we consider here in (B.1) leaves no room for such choice. Nevertheless, more generally, it is resources invested in appropriation versus those invested against it that decides the contest success function shown in (B.1). Then, there could be another equilibrium in which the rich tax themselves and devote resources to defend against extralegal appropriation. For a model of extralegal appropriation and production with offensive as well as defensive fortifications, see Grossman and Kim (1995). For a relevant discussion, also peruse Bates, Greif and Singh (2002).
} 
If the appropriation risk is relatively high (because the incomes of the poor are low relative to the wealthy) and the technology of appropriation is potent (such that $B$ in (B.1) is fairly large), but coordination among the rich is not prohibitively costly, then either the risk-sharing or the appropriation-cum-stagnation equilibrium would emerge. Furthermore, even if the coordination costs of the two latter equilibria are similar, the risk-sharing equilibrium is dynamically efficient, whereas the appropriation-cum-stagnation equilibrium is not. Hence, as long as the coordination costs of the risk-sharing equilibrium are not much higher than the appropriation-cum-stagnation equilibrium, the former is more likely to emerge as the equilibrium.

While this exposition is agnostic in terms of the specific social arrangements that could emerge in a risk-sharing equilibrium, the cultural and institutional constraints we discussed in the body of our main paper presumably dictated the specific social form of the risk-sharing arrangements that emerged in equilibrium (i.e., kin-based versus non-kinship risk-sharing). 